\title{
Aeroderivative Gas Turbine Back-up Capability with Compressed Air Injection
}

\author{
Kamal Abudu $\quad$ "Uyioghosa Igie Ioannis Roumeliotis Artur Szymanski Giuseppina Di Lorenzo \\ School of Aerospace, Transport and Manufacturing \\ Cranfield University \\ Cranfield, Bedfordshire, MK43 0AL \\ United Kingdom \\ *Email: u.igie@cranfield.ac.uk
}

\begin{abstract}
The transition to more renewable energy sources of power generation is associated with grid instability and the need for backup power, due to their intermittency. This provides an opportunity for gas turbine engines, especially the aeroderivative (AD) types that generally have higher ramp rates than heavy-duty engines. Nonetheless, higher ramp rates are still necessary to meet more stringent grid requirements, with increased renewables subscription. The study examines ramp rate improvements and performance enhancement through compressed air injection at the back of the high-pressure compressor (HPC). Two configurations of $\mathrm{AD}$ engines are considered in the investigation. In-house gas turbine performance simulation software has been used to simulate the steady-state and transient operations for design and off-design performance. Compressed air injection in the study is facilitated by an assumed compressed air storage or an external compressor. The steady-state analysis for power augmentation shows that for the two-spool engine with fixed speed low-pressure compressor (LPC), a $16 \%$ increase in power is obtained with $8 \%$ of flow injection. The other engine that is intercooled and consists of a variable speed LPC with power turbine shows a $21 \%$ increase in power for the same injection amount. Above $8 \%$ injection, the HPC of both engines tends towards an adverse rise in pressure ratio. However, up to $15 \%$ of flow injection is allowed before the surge point. It is seen generally that the operating point of the LPC moves away from surge, while the opposite is the case for the HPC. For transient simulations focused on ramp rates, the better improvements are shown for the intercooled engine that runs at variable speed. This is a ramp rate improvement of $100 \%$ with air injection, while that of the other engine increases by $85 \%$.
\end{abstract}

Keywords: flexibility, air injection, retrofit, gas turbine, ramp rate, power augmentation 


\section{INTRODUCTION}

By 2050, the share of electricity generated from renewables is expected to triple, mainly due to the increase in wind and solar energy power subscription [1]. However, their intermittency and current limitations of not providing synchronous inertia to power or frequency fluctuations make gas turbines a promising back-up system. This adds to the fact that gas turbines provide on-demand power and are relatively cleaner than other fossil-fuelled plants. Heavy Duty (HD) gas turbines offer an advantage of larger inertia and power output over the Aeroderivative (AD) type engines. However, the latter, that is the focus of this paper, is known to have superior flexibility that is related to their sizes/compactness, design (often multiple spools), higher power to weight ratio and better reliability.

The flexibility criterion investigated here is the ramp rate capability that indicates how fast these engines can attain a given power per minute. It infers how fast an engine can respond to a short-fall in power from renewable generation. In power generation, $\mathrm{AD}$ engines are typically used to satisfy peak demand as they generally offer superior ramp rates in comparison to their HD counterparts as shown in Figure 1. AD engines have found an application in significant projects like the LM6000 Hybrid Electric Gas Turbine integrated with a 10MW/ 4.3 MWh battery storage to support the Southern California Edison renewable capacity [2]. Another example includes the 800MW CPV Sentinel that consists of the LMS100 AD engine which supports renewables at peak periods [3].

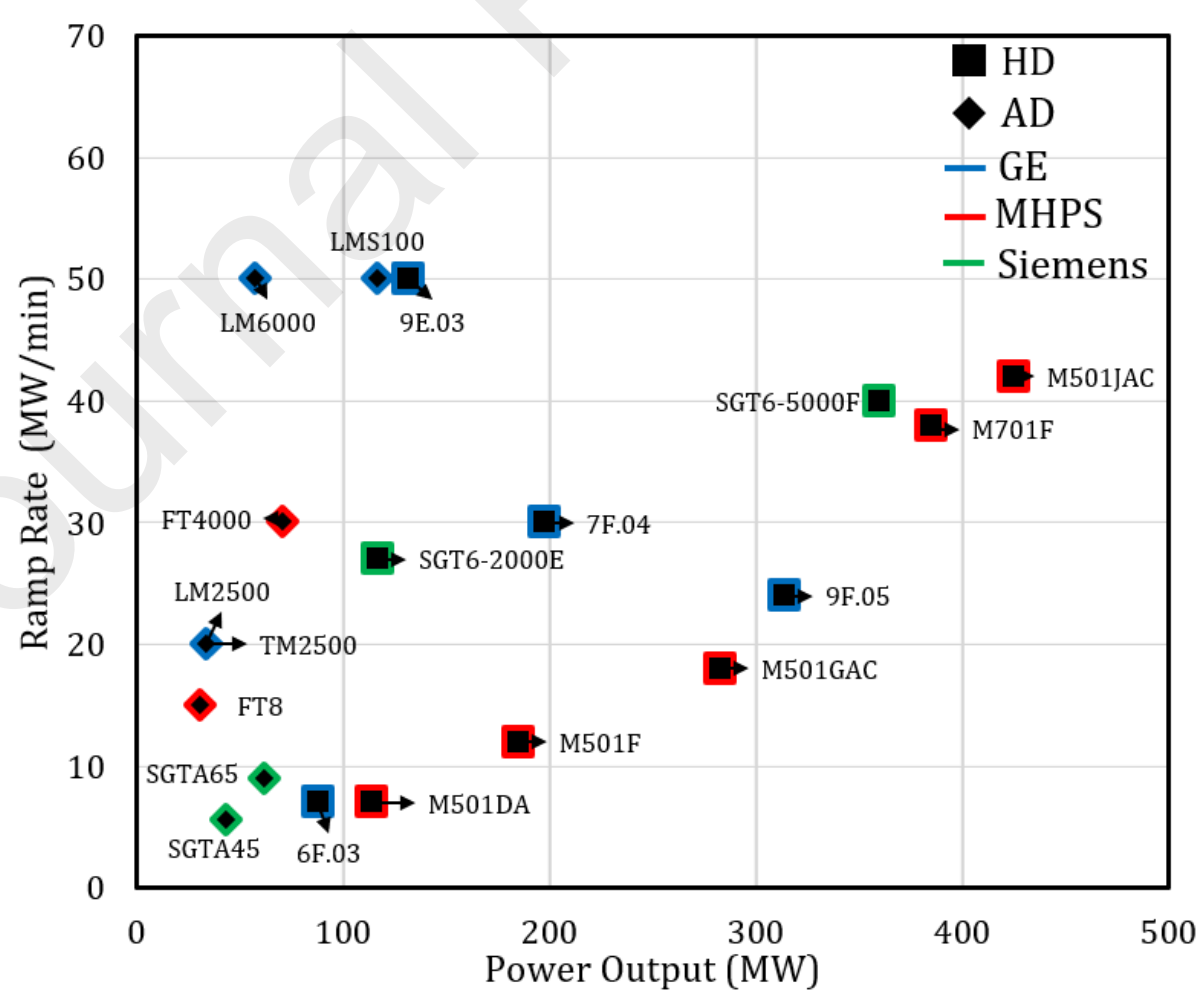

Figure 1 Gas turbine ramp rates for $\mathrm{HD}$ and $\mathrm{AD}$ engines across manufacturers 
The demand for electric power can increase significantly at peak times (like evenings) when renewable power (especially solar) typically reduces. The imbalance is shown in Figure 2; that shows the relationship between peak demands in evenings and reduced renewable power generation. These plots show the power demand within 8 hours in all seasons and reducing renewable capacity in Great Britain (GB). It suggests that with more renewable power, the difference between the generation and peak demand becomes more significant, thereby requiring a fast dispatchable generation through high ramp rates to close the gap.
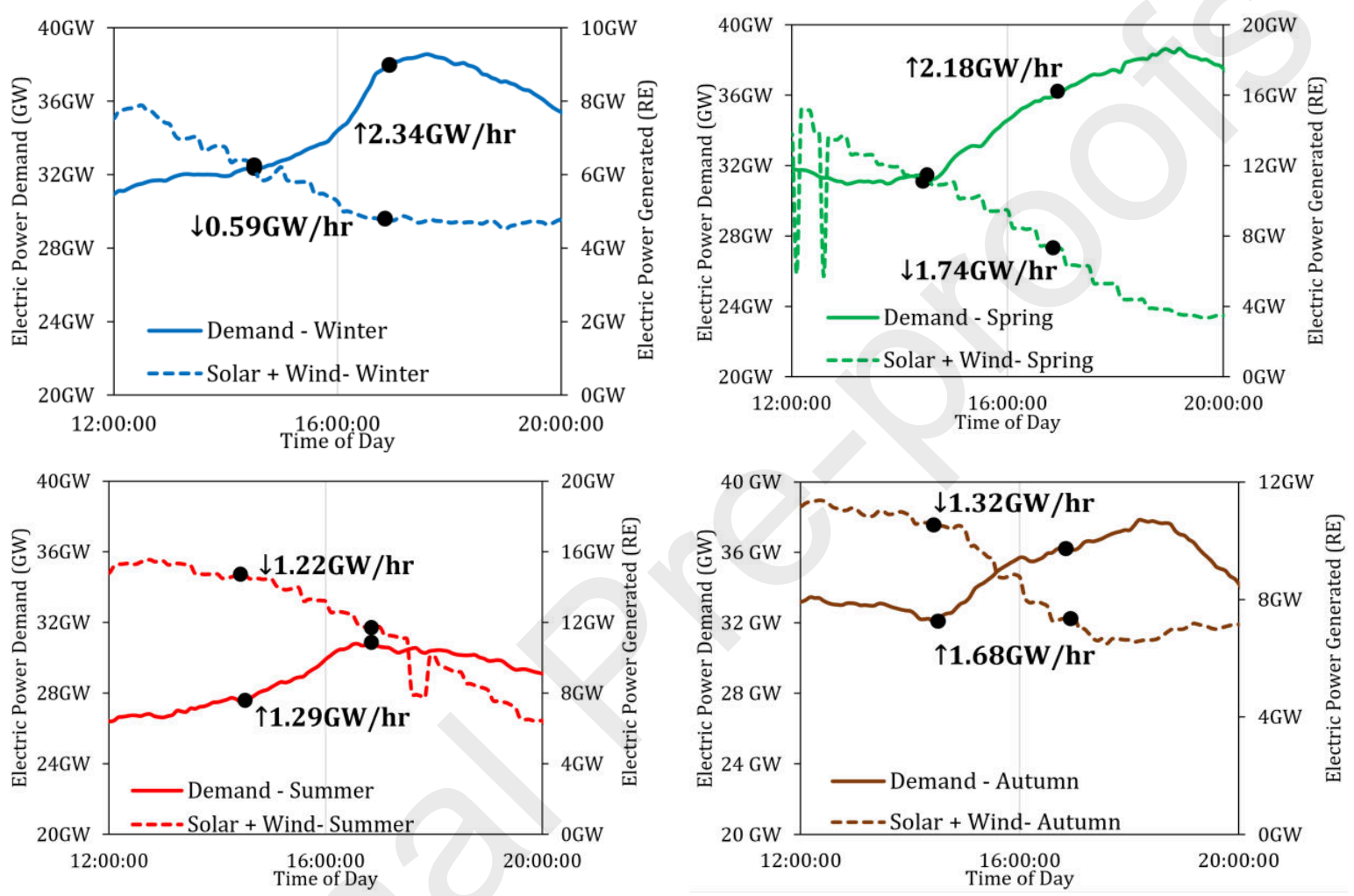

Figure 2 Power demand and renewable energy generation for a given period of the day [4]

Compressed Air Energy Storage (CAES) has been applied with a decoupled GT (compressor and turbine section operating independently) as shown in the Huntorf power plant commissioned in 1978, in Germany, and the McIntosh power station that was commissioned in 1991, in the United States [5]. In these applications, the decoupled compressor is driven by an electric motor, and the pressurised air is stored in a cavern. The stored air is then used when needed, by injecting it into the combustor and subsequently, to the decoupled turbine for power.

The area of the study presented here applies to a typical gas turbine configuration in which the turbine drives the compressor, however, has not been applied for commercial use. In practice, the closest example of this is shown by Powerphase [6] that used centrifugal compressors to inject air into an AD engine for power augmentation. Another related example is the bleed start for aero engines. This 
requires bleed air from an auxiliary power unit to a jet engine's turbine starter (small air turbine connected to the engine shaft through a clutch) to throttle up the jet engine to self-sustaining speeds. This could also involve direct cross bleed air from one engine to another engine when one has reached its self-sustaining speeds [7].

The impact of compressed air injection is now being examined more widely for power augmentation and ramp-up rates improvement, within power generation. Injecting compressed air into a gas turbine engine provides additional mass flow for power augmentation $[8,9,10,11]$ in steady-state and can be used to improve the transient ramp rate performance [8, 12]. For augmentation, Coriolano S. [13] examines the augmentation benefit of combining a small CAES system in two configurations. The first configuration, termed CAES air injection (AI) obtained a power increase of $30 \%$ with $14 \%$ injection rate (wrt inlet). The second setup which included an air expander, improved power by $36 \%$. The article shows a storage efficiency of $70 \%$ for the best operating scenario and confirms an adequate surge margin of $8 \%$ during air injection. Igie et al. [9] evaluate the implication of energy storage demand (extractions and injections) on the performance and operability of a single shaft gas turbine. The study indicates an increase in power output of over $40 \%$ with an air injection rate of $20 \%$ (wrt inlet), also proposing a maximum of $17.5 \%$ as safer for stall avoidance shown in the rear stages of the multi-stage model. The work as well proves that the compressor pressure ratio distribution influences these operational stall margins. Others studies such as Jubeh and Najjar [14] and Jeong et. al. [15] highlight the implication of compressed air injection into the gas turbine. However, these studies all focus on the single-shaft engine or the HD engine, and not the AD type engine that is considered in this work.

Gas turbine ramp rates are typically limited by the rate of change of combustion temperature which determines engine life. Faster ramp rates can be achieved by increasing the rate of fuel supply, however at the expense of the engine's life consumption (increased thermal fatigue). The typical ramp rates for $\mathrm{AD}$ engine provided in Figure $\mathbf{1}$ also shows a wide variation in response rate across engine manufacturers and a maximum of $50 \mathrm{MW} / \mathrm{min}$ (for ADGT), that is $50 \%$ less than the expected future value of $75 \mathrm{MW} / \mathrm{min}$ [16] for new and existing engines. Gonzalez-Salazar et al. [16] suggest that gas turbines are expected to increase their ramping capability by $70 \%-100 \%$ to accommodate for higher renewable power generation. Kim et al. [12] evaluate the optimum injection schedule for integrating CAES with a gas turbine. The authors focus on the injection schedule which was optimized using Genetic Algorithm. The article theoretically proves ramp rate improvements, from the storage system integration, without adverse combustion temperature changes. Abudu et al. [8] investigate a similar case with compressed air injection for a HD engine. The study concentrates on quantifying ramp rate improvements realized from air injection at varying rates for a HD engine. The authors show that the ramp rates improve by $10 \%$ for every added $2 \%$ airflow injected. However, operational concerns such 
as surge margin reduction and faster turbine entry temperature (TET) increase were seen to be dominant at the maximum airflow injection of $8.2 \%$ wrt inlet.

Investigations about ramp rate improvements have mostly been conducted by OEMs through design improvements. Balling [17] and GE Power [18] describe details on design modifications for Siemens and GE engines respectively, that enable faster response rate. The modifications include combined GT and steam cycle ramping, hot gas path upgrades, and advanced control modules. The closest to storage mentioned is that of battery that helped to improve the LM6000 AD engine ramp rates as reported in Decampli and Liang [2]. The review of literature does not show any existing research study of compressed air injection on $\mathrm{AD}$ engines that have a more complex design than the HD or the singleshaft design. The multi-spool design of $\mathrm{AD}$ gas turbines is known to generally offer better flexibility (e.g. superior starts and stops that are typical of their aerospace heritage). Nevertheless, the design can also be a limiting factor when one of the shafts is fixed, as in the case of one of the engines investigated in this study. Despite their already high ramp rates as shown in Figure 1, these engine types are also required to achieve higher ramp rates as shown in Gonzalez-Salazar et al. [16]

This study as such, shows for the first time:

- the potential ramp rate improvement of $\mathrm{AD}$ engines for enhanced flexibility using compressed air injection (transient simulations)

- the operability of the engine during such injection, concerning the more complex design (multispools) and the interaction between the compressor sections

- the potential increase in engine performance as a function of airflow injection rate

- the influence of different $\mathrm{AD}$ engine configurations, with and without an intercooler and a power turbine, in regards to power augmentation.

\section{ENGINES UNDER INVESTIGATION}

Two AD engines are considered in this study; they have been inspired by the GE LM6000 and LMS100 multi-spool configurations. The LM6000 is selected because of its high application in power generation, while the LMS100 is chosen for its added design complexity (intercooling) and size. In this study, the engines are referred to as Two-Spool 56MW (TS56) and Two-Spool intercooled 118MW (TSI118), respectively. The TS56 gas turbine generates 56MW and consist of an LPC, HPC, HPT and LPT of 5, 14, 2 and 5 stages, respectively. It also features an annular combustor and is equipped with variable inlet guide vanes and stator vanes. A key design feature of this engine is the LP shaft/spool which operates at a rotational speed of $3600 \mathrm{rpm}$. This enables direct coupling to a generator without the need for a speed reduction gearbox [19]. The rotational speed of the LP shaft is constant (as in many HD engines), while the HP shaft rotates freely at a varied rotational speed; this can be up to three times that of the LP shaft. Unlike the LM6000, the LMS100 consist of a power turbine. The gas generator section 
of the engine operates at varied rotational speed (both LP and HP shafts). The power turbine is not mechanically connected but aerodynamically matched to the LPT section. The LPT runs at a different rotational speed that is determined by the generator. The $118 \mathrm{MW}$ engine has greater flexibility as a result of the free variation of speeds of both shafts and consists of 20 compressor stages split two ways (LP-6 and HP-14), and 9 turbine stages divided amongst the HPT(2), LPT(2) and PT(5). The engine also features a simple annular combustor (SAC) and an intercooler which amounts to a superior pressure ratio than the other engine. Both engines described are derived from the CF6 family of aircraft engines and are available in CCGT configuration [20].

The GT performance is modelled using Turbomatch, Cranfield University's in-house software. The code has design, off-design, steady-state and transient performance simulation capabilities. Thus, the capability to simulate gas turbine cycles, including specified performance and operability requirements. Major components (like compressor, combustor and turbine) operation is determined by an integrated set of standard performance maps. Variable geometry (IGVs and VSVs) and bleed-off valves effect is also possible [21]. In addition, control constraints such as combustor outlet temperature (COT), shaft speed, and power output can be specified for computations. Further details of some of the calculation procedures are available in Igie et al. [9, 22]. Figure 3 is a schematic of the TS56 and TSI118 (top and bottom, respectively), showing the architecture and interconnections of the model. Both engine models described here are consistent with the thermodynamic performance of the actual engines indicated earlier. Similarly, the models comprise of the LP and HP shaft that drives the respective compressor and turbine sections. The TSI1 18 consists of an intercooler and a PT that differentiates it from the TS56. Their HP turbine cooling flows are accounted for and introduced at the inlet of the HPT, in line with ISO standard [23]. As shown in the figure, external compressed air is injected into the engines at the back of the HPC sections (station 3).

TS56

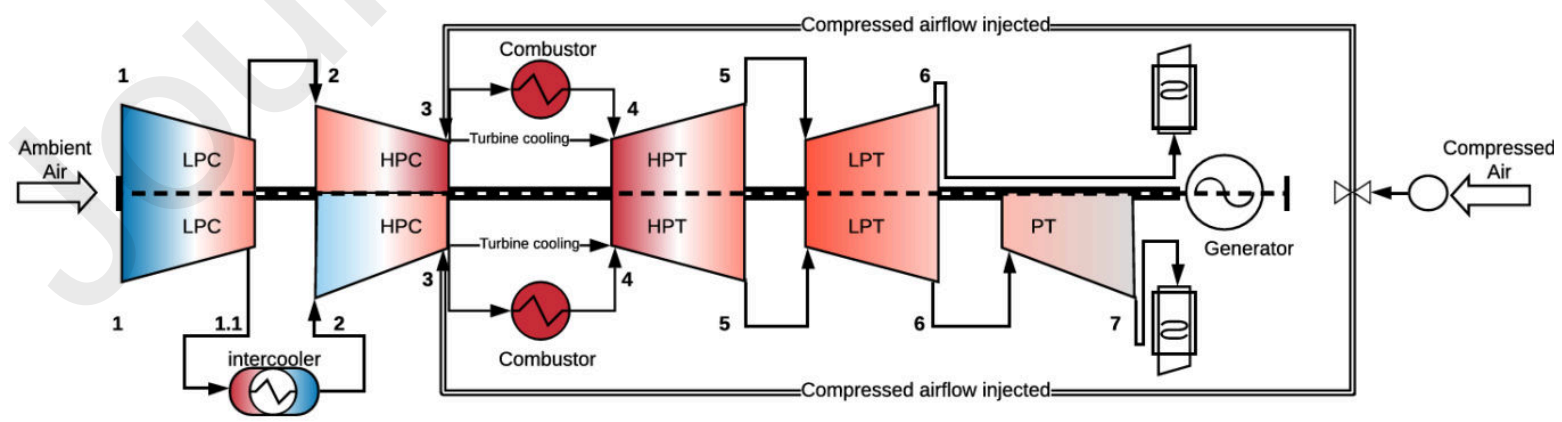

TSI118

Figure 3 Engine schematic for TS56 (top) and TSI118 (bottom)

For the TSI118 engine with the intercooler, further effort has been made to account for the variability of the effectiveness at off-design scenarios. The effect of the intercooler is a reduction of the HPC inlet 
temperature $\left(\mathrm{T}_{2}\right)$ indicated in Equation 1. As shown in Figure 4, this is a function of Tamb: the ambient temperature, $\mathrm{T}_{1.1}$ : the inlet temperature to the intercooler and $\varepsilon$ which is the intercooler effectiveness that is influenced by the corrected mass flow of the LPC [24]. The $T_{2}$ is calculated from the related parameters in Equation 1 and Equation 2 as subjects of the formulae, where $D$ and $O D$ signify design and off-design simulations respectively. The variable effectiveness approach implemented in this study also described from Walsh \& Fletcher [24], allows for the variation of the HPC operating point in offdesign simulations.

The design point performance of both engines is shown in Table 1, at ISO conditions. A comparison of both engines baseline performance can be made with this table. Similar losses are specified, like pressure losses; identical surge margins, compressors, turbines and combustion efficiencies are also assumed based on typical values and best practice. Table 2 shows the parameters that are specified design objectives and the outcomes of the calculations in comparison to the OEM published data [19, 20]. It shows an acceptable maximum percentage error below $0.5 \%$ for these calculated design parameters.

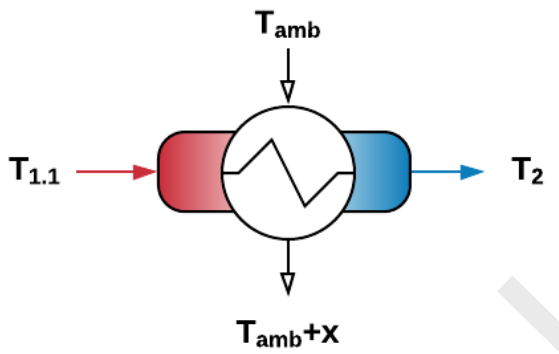

$$
\begin{array}{cc}
T_{2}=T_{1.1}-\left(\varepsilon \cdot\left(T_{1.1}-T_{a m b}\right)\right) & \text { Equation 1 } \\
C M F_{1.1}=\frac{M_{1.1} \sqrt{ } T_{1.1}}{P_{1.1}} & \text { Equation 2 } \\
\varepsilon_{O D}=1-\left(\frac{C M F_{1.1-O D}}{C M F_{1.1-D}}\right) \times\left(1-\varepsilon_{D P}\right) & \text { Equation 3 }
\end{array}
$$

\begin{tabular}{|c|c|c|c|}
\hline Design Parameters & LM6000 & LMS100 & Comment \\
\hline Ambient conditions & \multicolumn{2}{|c|}{ ISO } & - \\
\hline Inlet mass flow $(\mathrm{kg} / \mathrm{s})$ & 165.8 & 245.2 & Evaluated from public data \\
\hline Inlet pressure loss (bar) & $1 \%$ & $1 \%$ & Evaluated from public data \\
\hline LP Compressor Pressure ratio & $2.6: 1$ & $3.9: 1$ & Evaluated from public data [19]/ [20] [25] \\
\hline LP Compressor Efficiency & $84 \%$ & $85 \%$ & assumed \\
\hline LP Compressor Surge Margin & $15 \%$ & $15 \%$ & assumed \\
\hline Intercooler Pressure loss & & $8 \%$ & Evaluated from public data [24] \\
\hline Effectiveness (design) & & $88 \%$ & {$[26][27]$} \\
\hline HP Compressor Pressure ratio & $13: 1$ & 10.9:1 & Evaluated from public data [19]/ [20] [25] \\
\hline HP Compressor Efficiency & $85 \%$ & $85 \%$ & assumed \\
\hline HP Compressor Surge Margin & $15 \%$ & $15 \%$ & assumed \\
\hline Combustor pressure loss & $4 \%$ & $4 \%$ & Evaluated from public data [24] [28] \\
\hline Combustor Efficiency (\%) & $99 \%$ & $99 \%$ & Evaluated from public data [29] \\
\hline Combustor Outlet Temperature & $1600 \mathrm{~K}$ & $1643 \mathrm{~K}$ & Evaluated from public data [30]/ [31] \\
\hline HP Turbine Blade cooling flow & $13 \%$ & $15 \%$ & Evaluated from public data [32] \\
\hline HP Turbine Efficiency (\%) & $87 \%$ & $88 \%$ & Assumed \\
\hline IP Turbine Efficiency & & $89 \%$ & Assumed \\
\hline
\end{tabular}

Figure 4 Intercooler schematic- TSI118

Table 1: Engine models DP performance specification 


\begin{tabular}{|l|c|c|l|} 
LP Turbine Efficiency & $88 \%$ & $89 \%$ & Assumed \\
\hline Exhaust pressure Loss & $1.5 \%$ & $1.5 \%$ & Evaluated from public data [24] \\
\hline Fuel lower heating value & $45.5 \mathrm{MJ} / \mathrm{kg}$ & $45.5 \mathrm{MJ} / \mathrm{kg}$ & - \\
\hline
\end{tabular}

Table 2: DP Performance - calculated parameters and \% error

\begin{tabular}{|l|c|c|c|c|c|c|}
\hline Performance Parameters & LM6000 [19] & TS56 & \%Error & LMS100 [20] & TSI118 & \%Error \\
\hline Power Output & $56 \mathrm{MW}$ & $56 \mathrm{MW}$ & $0 \%$ & $118 \mathrm{MW}$ & $118 \mathrm{MW}$ & $0.00 \%$ \\
\hline Net Thermal Efficiency & $40.00 \%$ & $40.00 \%$ & $0.00 \%$ & $43.60 \%$ & $43.60 \%$ & $0.00 \%$ \\
\hline Exhaust gas Temperature & $743 \mathrm{~K}$ & $745.5 \mathrm{~K}$ & $0.34 \%$ & $713 \mathrm{~K}$ & $713.3 \mathrm{~K}$ & $0.05 \%$ \\
\hline
\end{tabular}

\section{POWER AUGMENTATION}

The section focuses on the steady-state injection of compressed air, to increase the power output. The air can be obtained from CAES storage, as described in Coriolano [13, 33]. In practice, this stored compressed air (that can be up to 70 bar) would need to be expanded to suitable pressure allowable for the engine. Alternatively, the compressed air can be from another compressor; these options are illustrated in Figure 5. In this study, for simplicity, it has been assumed that the temperature and pressure of injections are similar to the varying air properties at the compressor discharge. Igie et al [9] show the implications of varied injection temperatures on the injection performance for a single-shaft engine.

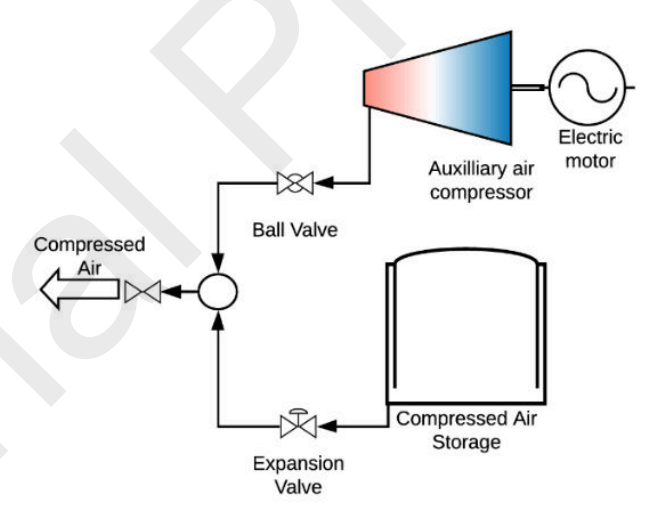

Figure 5 Schematic showing possible sources of compressed air

The compressed air is injected as a percentage of the HPC discharge flow (location 3 wrt Figure 3) up to $15 \%$ while maintaining constant combustion temperature. The effect of this operation on power output, thermal efficiency and fuel flow is shown in Figure 6 for the TS56 and TSI1 18. The increased airflow requires additional fuel flow to maintain the reference combustion temperature. However, this rise in the fuel flow is comparatively smaller as shown in the figure; it is not in proportion to the power augmentation and causes a rise in thermal efficiency. It is important to state that the rise in power output amounts from the greater work done by the turbine in relation to the compressor, with additional air and fuel flow. 
In this operation, the airflow injection causes a rise in HPT work and subsequently the rotational speed of the HPC. This brings about an increase in the inlet mass flow (IMF) and overall pressure ratio (OPR) as shown in Figure 7. The effect of these is a rise in the compressor work of the HPC that consequently leads to an increase in the compressor discharge temperature (CDT) shown. As the CDT rises, the turbine cooling flow temperature is also higher, causing an increase in the TET (also given that the combustor outlet temperature - COT is fixed). The exhaust gas temperature (EGT) drops, despite the increase in TET, due to an increase in compressor pressure ratio which results in a higher expansion in the turbine sections.

目TS56 圆TSI118

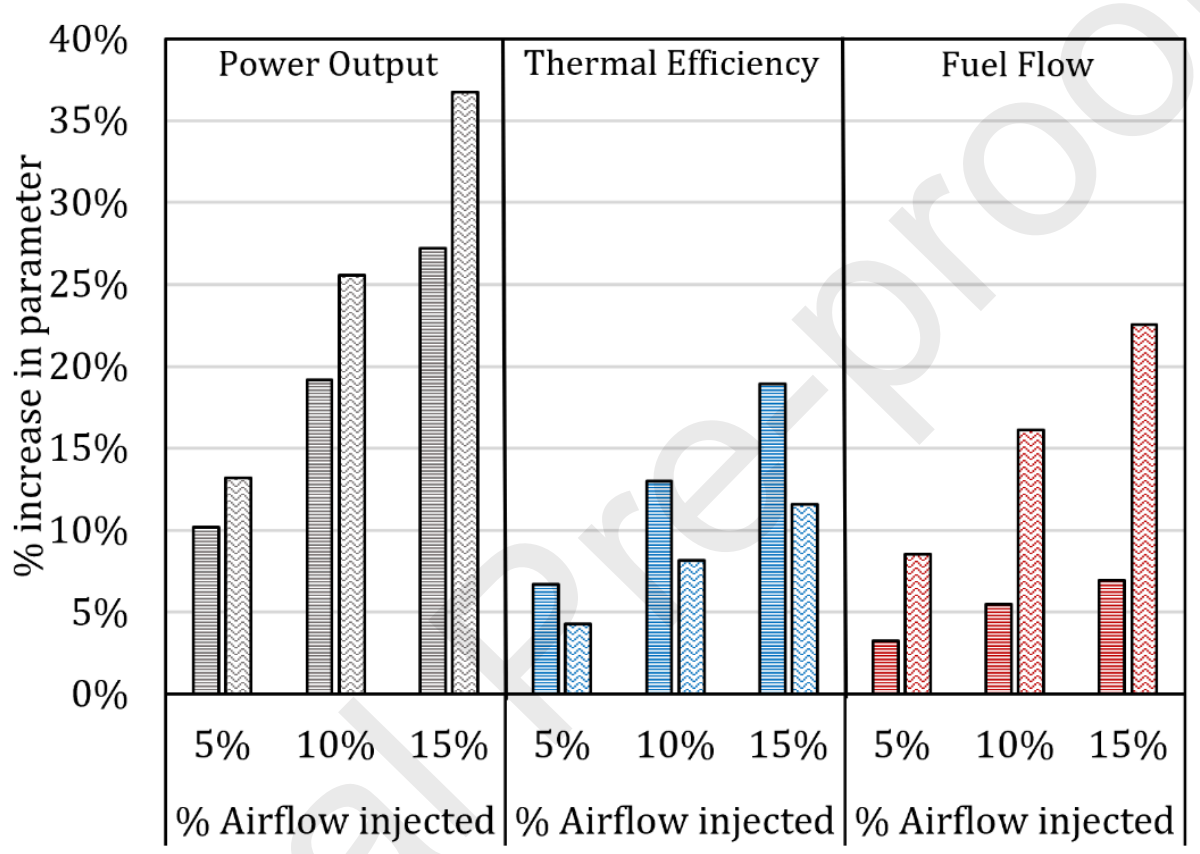

Figure 6 Effect of airflow injection on performance parameters- TS56 \&TSI118 


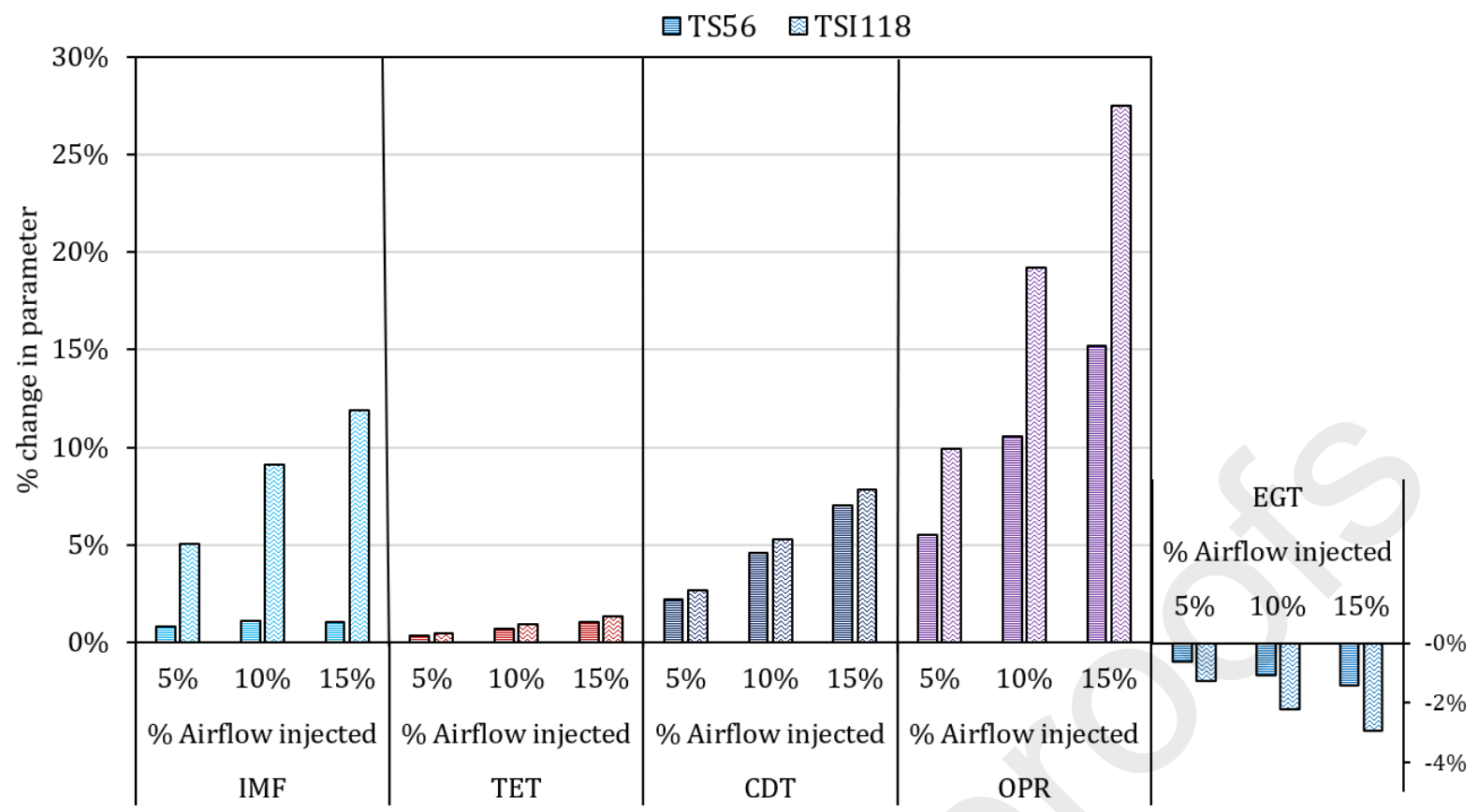

Figure 7: Effect of flow injections on operating parameters- TS56 \&TSI118

Figure 6 and Figure 7 show that an increased injection rate amplifies these changes discussed. It also shows that the change in power output, fuel flow and OPR (for the same injection rate) is higher for the TSI1 18 engine. However, the thermal efficiency increase for the TS56 is greater and attributed to the minimal increase in fuel flow in comparison to the power augmentation achieved. For the TSI118, the variability of the LPC and HPC shafts bring about a further increase in the IMF that explains the higher rate of increase in the fuel flow. This operation is more constrained for the TS56 for which only the HPC rotational speed varies; therefore, the increase in IMF and fuel flow is less. The comparative design constraints for both engines are highlighted in Figure 8 and Figure 9, respectively. These show that for the TS56, with increasing compressed air injection, the LPC pressure ratio reduces, also moving from a lower corrected mass flow (CMF) to a higher value. The opposite is the case for the HPC which tends towards the surge line albeit an increase in its inlet CMF. Hence the OPR change observed is mainly due to the pressure ratio rise in the HPC that is facilitated by the increase in rotational speed. The variable speed LPC and HPC of TSI118 show similar directions of change (increasing shaft speed) which is similar to the HPC of TS56. The off-design behaviour of these compressors is verified using Equation 4 to Equation 7 that applies to the TS56 numbering in Figure 3. 

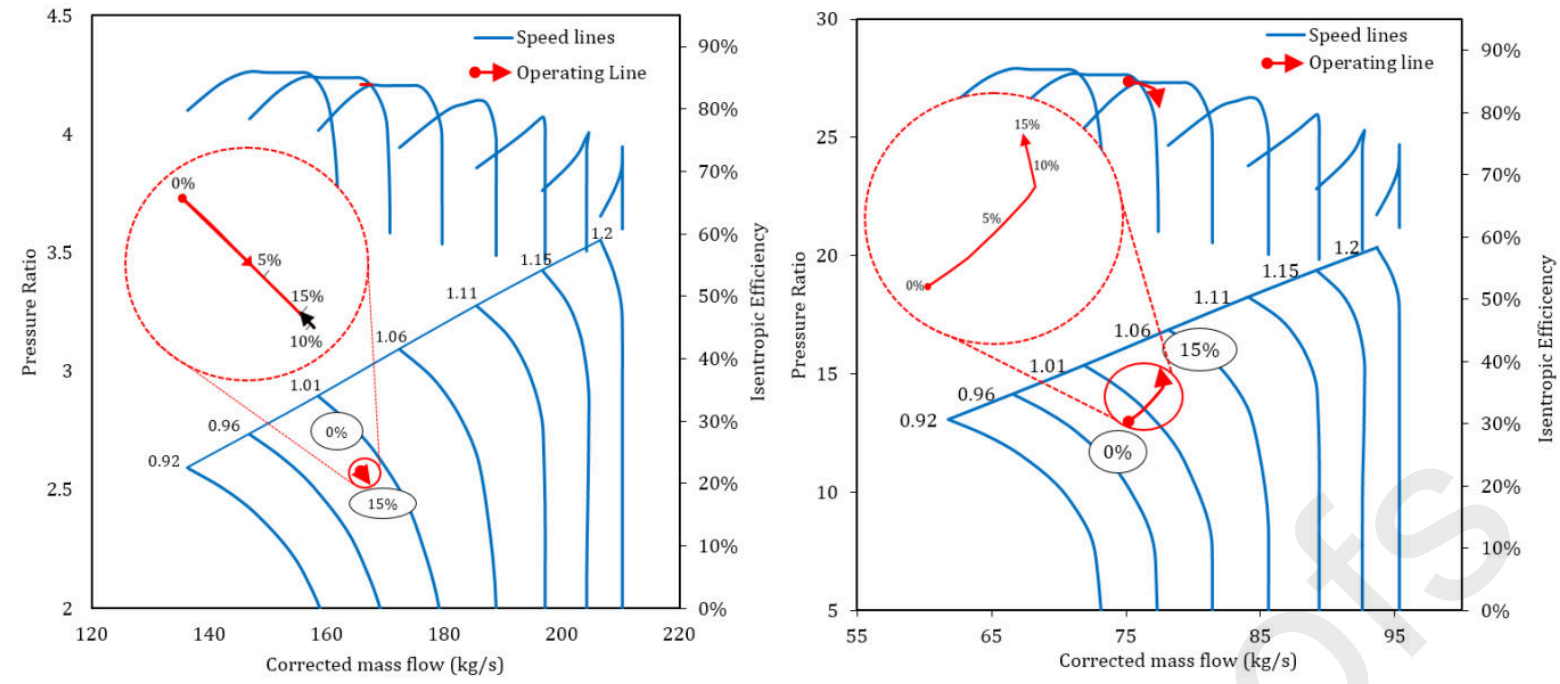

Figure 8 Operating points of LPC (left) \& HPC (right) maps during injection -TS56
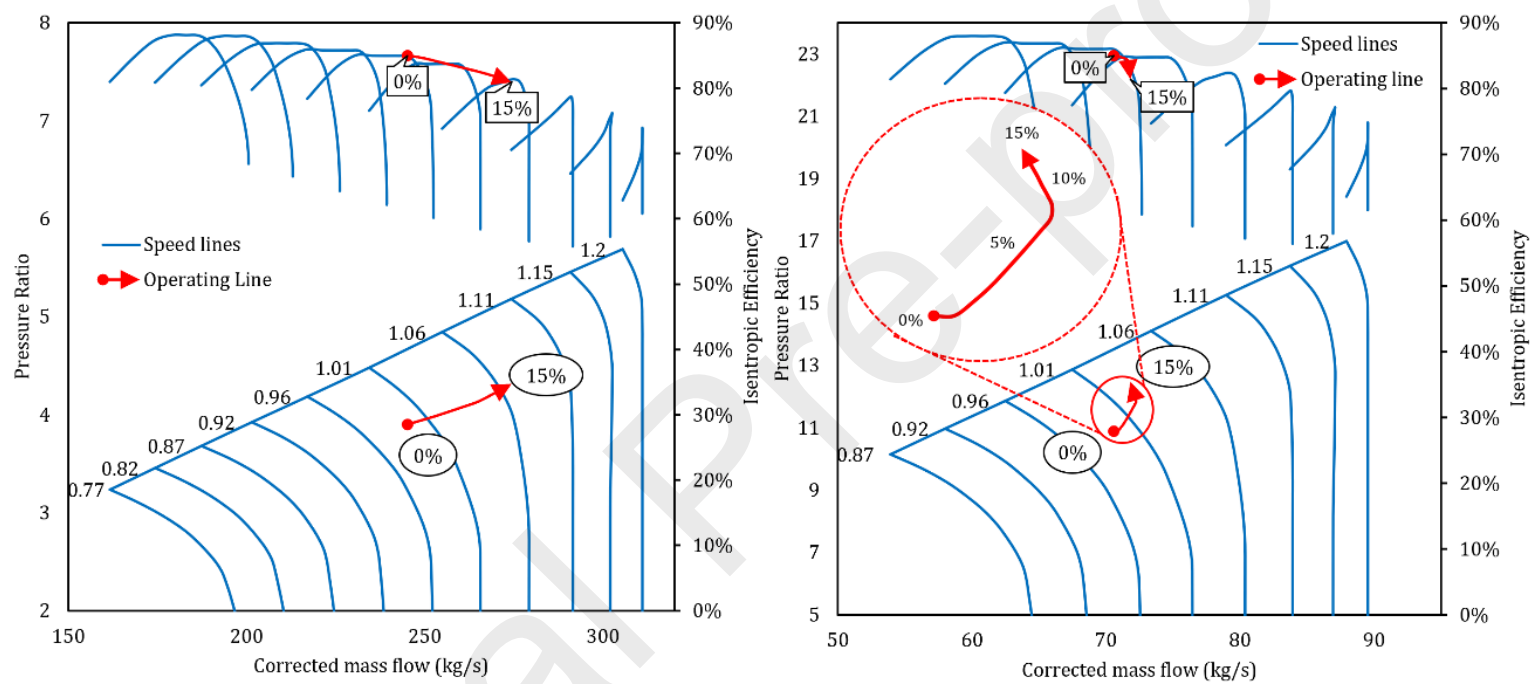

Figure 9: Operating points of LPC (left) \& HPC (right) maps during injection - TSI118

$$
\begin{gathered}
\frac{\Delta T_{32}}{T_{2}}=\frac{\Delta T_{45}}{T_{5}} \cdot \underbrace{\frac{T_{4}}{T_{2}}}_{a_{2}} \cdot \underbrace{\frac{C p_{g}}{C p_{a}}}_{a_{3}} \cdot \underbrace{\frac{W_{4}}{W_{2}}}_{a_{4}} \underbrace{W_{2}}_{a_{5}} \\
\frac{W_{4} \sqrt{T_{4}}}{P_{4}}=\frac{W_{2} \sqrt{T_{2}}}{P_{1}} \cdot \underbrace{\frac{P_{2}}{P_{3}}}_{b_{2}} \cdot \underbrace{\frac{P_{3}}{P_{4}}}_{b_{3}} \cdot \underbrace{\sqrt{\frac{T_{4}}{T_{2}}}}_{b_{4}} \cdot \underbrace{\frac{W_{4}}{W_{2}}}_{b_{5}} \underbrace{W_{2}}_{b_{6}} \\
\frac{W_{2} \sqrt{T_{2}}}{P_{2}}=\frac{W_{1} \sqrt{T_{1}}}{P_{1}} \cdot \underbrace{\frac{P_{1}}{P_{2}}}_{c_{2}} \cdot \underbrace{\sqrt{\frac{T_{2}}{T_{1}}}}_{c_{3}} \cdot \underbrace{\frac{W_{2}}{W_{1}}}_{c_{4}}
\end{gathered}
$$

Equation 4

\section{Equation 5}

Equation 6

Considering Equation 4, assuming the turbines operate choked during the injection of airflow, the variation of the HPC non-dimensional speed of TS56 can be justified. The increased airflow through the combustor and turbine alters the generally assumed constant mass flow ratios in engine behaviour 
prediction. Consequently, the term $\left(a_{5}\right)$ increases, thereby requiring variations in $a_{1}-a_{4}$ to balance equ. 4. Terms $\mathrm{a}_{2}-\mathrm{a}_{4}$ are considered approximately constant from the assumption of a choked turbine $\left(\mathrm{a}_{2}\right)$, constant speed of LPC and minor variations in TET $\left(a_{3}\right)$, and minimal changes in gas properties $\left(a_{4}\right)$. As a result, term $\mathrm{a}_{1}$ increases and causes a corresponding rise in TS56's HPC non-dimensional speed as noticed in Figure 8. The flow compatibility relationship between the HPC and HPT for TS56 is represented by Equation 5. Similarly, term $b_{6}$ (which is equal to $a_{5}$ ) increases during airflow injection and suggests variations in other parameters of Equation 5. From the aforementioned assumptions, terms $b_{1}$ and $b_{5}$ are approximately constant, while $b_{4}$ (which is the combustor pressure loss) changes insignificantly. Therefore, variations and possible reductions in terms $b_{2}$ and $b_{3}$ are required. The unique operation of the HP spool defines the operating point of the HPC by the intersection of the new speed line (from Equation 4) and the HP spool temperature ratio $\left(a_{3}\right)$ at a higher inlet corrected mass flow $\left(b_{2}\right)$ and pressure ratio $\left(b_{3}\right)$. The effect of the increased HPC inlet corrected mass flow is determined using Equation 6; in which term $c_{1}$ increases. Therefore, the terms $c_{2}-c_{5}$ can be altered to balance the relationship. However, terms $\mathrm{c}_{2}, \mathrm{c}_{4}$ and $\mathrm{c}_{5}$, are approximately constant due to minor variations in inlet mass flow at high speeds $\left(\mathrm{c}_{2}\right)$, constant LP spool speed $\left(\mathrm{c}_{4}\right)$, and minimal compressor bleeds $\left(\mathrm{c}_{5}\right)$. The effect (of an increase in $c_{1}$ ) is an increment in term $c_{3}$ (inverse of LPC pressure ratio); which causes the prior reduction in LPC pressure ratio noticed in Figure 8.

$$
\underbrace{\frac{\Delta T_{21}}{T_{1}}}_{d_{1}}=\underbrace{\frac{\Delta T_{56}}{T_{5}}}_{d_{2}} \cdot \underbrace{\frac{T_{5}}{T_{1}}}_{d_{3}} \cdot \underbrace{\frac{C p_{g}}{C p_{a}}}_{d_{4}} \cdot \underbrace{\frac{W_{5}}{W_{1}}}_{d_{5}}
$$

\section{Equation 7}

The predictions are consistent for TSI118, however, the assumption of constant spool speed for the LPC is not applicable. As such, the LPC of TSI118 behaves differently and is explained by considering Equation 7 (the LP spool work compatibility relation). The increase in LP spool speed (noticed in Figure 9) occurs as term $d_{5}$ of Equation 7 increases. Terms $d_{2}-d_{4}$ are approximately constant due to choked PT (fixed LPT PR), choked HPT (fixed HPT PR which fixes $\mathrm{T}_{5}$ ), and minor changes in heat capacities, respectively; thus, increasing term $d_{1}$ (LPC spool speed) to counter the increase in $d_{5}$. The HPC prediction for TSI118 is similar to TS56 as a common assumption of approximately constant $\mathrm{T}_{2}$ holds. It should, however, be noted that the almost constant LPC discharge temperature results from different conditions on the engines; constant LP spool speed for TS56 and intercooling for TSI118. Furthermore, a turning point is noticed on the operating line of TS56 at higher injection flow rates (above 8\%) that indicates an increase in pressure ratio (Figure 8). The effect occurs as the LPC satisfies the flow compatibility with the HPC which moves operation to a reduced corrected mass flow, higher pressure ratio and increased spool temperature ratio. As a result, the HPC operating line heads towards surge as significant pressure ratio rise is required to ensure the HPT remains choked. This phenomenon 
is also noticed on the HPC of TSI118, however, the LPC responds differently due to its ability to vary the speed (Figure 9).

This section has shown that power augmentation of the engines can reach up to $27 \%$ with $15 \%$ injection for the TS56, while for the TSI118, it is about 37\%. At this maximum injection rate investigated, the surge has not been reached, though the risk appears higher for the TS56 engine. Nevertheless, the adverse increase in the HPC pressure ratio of both engines is observed to be from $8 \%$ injection. Based on this $8 \%$ limit, the power augmentation is restricted to $16 \%$ and $21 \%$ for TS56 and TSI118, respectively. The compressor isentropic efficiencies in Figure 8 and Figure 9 indicate slight variations, with higher reductions observed for the HPC of the TS56, while it is the LPC for TSI118.

\section{RAMP RATE IMPROVEMENTS}

In addition to the power augmentation benefits, airflow injection has the potential to improve the ramp rate of gas turbines. This benefit is explored by performing transient ramp-up simulations of the engines with and without flow injection. The analysis is based on the following assumptions:

- Heat soakage effects are negligible

- No time delay in the fuel system

- Ramp up is restricted by combustor outlet temperature (COT) schedule

The computation method used is the constant mass flow method assumes the continuity of mass flow across components of the gas turbine. Essentially, it does not consider mass storage but accounts for inertial effect that is crucial in transient operation [34]. Figure A.1 of the Appendix shows a simplified computational procedure for the constant mass flow transient method. The calculation begins with a steady-state turndown to $50 \%$ power, which initiates the dynamic simulation by providing corrected mass flows of the turbine inlet and outlet (assumed constant). A new power setting achieved by a rise in TET is specified by the ramp rate, initial power and time step. The increased TET aids the calculation of the new turbine inlet pressure, which is used to define a new HPC pressure ratio and work. The constant corrected mass flows determine the expected turbine pressure ratio which implies temperature ratio through the isentropic relation. The new temperature difference across the turbine then dictates the HPT work and determines the HP spool surplus power. Consequently, the shaft acceleration is computed (using the HP spool's inertia, speed and surplus power) and suggests a new HP spool speed. A similar sequence of computation evaluates the LP spool surplus power. However, if the LP operates at a constant speed; its acceleration tends to zero as the surplus power is transferred to the generator. The sequence is repeated until the target power of $100 \%$ is achieved. It should be noted that the simplified procedure assumes minor variations in corrected mass flows, isentropic efficiencies, combustor pressure loss and gas properties, which are accounted for in the simulation code. 
Table 3 shows input data for the load ramp-up simulation for the engines as the focus of this section is the ramp-up of the engine and not turndown. The power output of the engine is reduced to $50 \%$ by 10 steady-state simulations, at 5\% intervals, to initialize the transient ramp up. Subsequently, the engine is ramped up to $100 \%$ in a transient manner. A ramp rate of $50 \mathrm{MW} / \mathrm{min}$ is specified for both engines as suggested by the OEM details $[19,20]$. The LPT and PT of the TS56 and TSI118 respectively, operate at the grid synchronization speed (3600rpm) and shaft inertia of approximately $2400 \mathrm{~kg} / \mathrm{m}^{2}$ is specified based on Calpine [35]. Similar rates of injection and time steps are set in the simulation for both engines, for the comparison of their augmented ramp rates.

Table 3: Input data for design transient simulation

\begin{tabular}{|l|c|c|}
\hline \multicolumn{1}{|c|}{ Input Parameter } & TS56 & TSI118 \\
\hline Preceding steady-state simulations & 12 & 12 \\
\hline Engine/PT rotational speed (rpm) & 3600 & 3600 \\
\hline LP/PT Rotor Inertia $\left(\mathrm{kg} / \mathrm{m}^{2}\right)$ & 2404 & 2400 \\
\hline IP rotational speed $(\mathrm{rpm})$ & & 6000 \\
\hline IP Rotor Inertia $\left(\mathrm{kg} / \mathrm{m}^{2}\right)$ & & 200 \\
\hline HP rotational speed (rpm) & 12000 & 12000 \\
\hline HP Rotor Inertia $\left(\mathrm{kg} / \mathrm{m}^{2}\right)$ & 100 & 200 \\
\hline Engine default ramp rate (MW/min) & 50 & 50 \\
\hline Engine default ramp rate (\%/min) & $89 \%$ & $42 \%$ \\
\hline Engine default surge margin & $15 \%$ & $15 \%$ \\
\hline Starting power output $(\%)$ & $50 \%$ & $50 \%$ \\
\hline Target power output $(\%)$ & $100 \%$ & $100 \%$ \\
\hline Time range $(\mathrm{s})$ & 100 & 100 \\
\hline Time step (s) & 0.05 & 0.05 \\
\hline Rate of airflow injection $(\% / \mathrm{s})$ & 0.5 & 0.5 \\
\hline
\end{tabular}

A default ramp-up schedule is defined by considering the engine's normal operation and the OEM defined ramp rate. The resulting ramp-up schedule is simulated in a transient operation from $50 \%$ to $100 \%$ of the power output, to provide the default combustion temperature schedule. The idea of the injection ramp-up is to maintain the COT schedule for minimal effect on engine life. However, some small differences persist due to the increase in fuel flow to overcome shaft inertia. Injection quantities of $2 \%-10 \%$ (based on the HPC flow) are considered at intervals of $2 \%$ with an injection rate of $0.5 \% /$ second. It is important to note that the respective injection cases indicated by values $(2 \%$, $4 \% \ldots 10 \%$ ) denote the maximum injection for their respective cases and not a constant value throughout their injection. For each case, the airflow is injected at the selected rate up to their maximum percentage of injection where it no longer changes. The respective limit of injection (by \%) is maintained until the full power is reached. For lower injections, the first instance of reaching their limit does not coincide with the full power. As such, the subsequent operation to full power is supplemented by the continuous increase in COT. 


\section{TS56 Ramp Rate and Compressor Behaviour}

The operating parameters for the default reference operation and 2\% injection ramp up for TS56 are compared in Figure 10. From the top-left of the figure, it can be noted that $2 \%$ is the maximum value injected for this case (not the starting value). In addition, this maximum value of injection is reached at 24 seconds, while beyond this point, the injection rate (\%) is accompanied by a gradual rise in COT. At 50.1 seconds the reference maximum power output is reached; this is a 3.5 seconds difference with the default ramp case as shown. Beyond this point in the graph, ramping is no longer considered, and the air injection is reduced gradually to return to normal operation at 53.6 seconds. Figure $\mathbf{1 0}$ also shows changes in the performance parameters as well as the rotational speeds of the LPC and HPC. Like air injection in steady-state, the increased HPT flow raises the HPC pressure ratio; this brings about a rise in the HP spool speed. As indicated in the figure, the spool speed increases and then stabilizes in the same direction of change of injection, while the LPC is constrained to be fixed. Furthermore, the increased pressure ratio and CDT of the HPC contribute to improvements in the efficiency of the GT during the injection ramp up as shown.

Figure 11 shows the LPC and HPC operating lines on their respective characteristic maps for the rampups. The left of the figure shows the changes in the operating point of the LPC, where $0 \mathrm{~s}$ is the start of the ramp and 56s is the end for the default case. A similar trend is shown for the injection case, and these indicate that the operating point moves towards a lower pressure ratio and higher compressor efficiency. For the HPC, a trend to higher pressure ratio and lower compressor efficiency is observed. The variations in operating points are as a result of the operational changes shown in Figure $\mathbf{1 0}$ and is justified by the earlier explanation provided for Figure 8.

Figure 12 shows the case of $9 \%$ injection with the corresponding changes in power output and COT. For this case, the maximum injection is reached at $38.2 \mathrm{~s}$ that coincides with the maximum power output. This is the maximum injection considered for this engine as no increase in COT is needed to facilitate the ramp rate beyond this point, unlike the case of $2 \%$ injection. Similarly, to return to normal operation, the injection is reduced until 53.6 seconds. It can be noted that in comparison to the default ramp rate, the maximum power output is reached 15.4 seconds sooner. Further details of the other injection rates are provided in Figures A2 - A4 of the Appendix. 

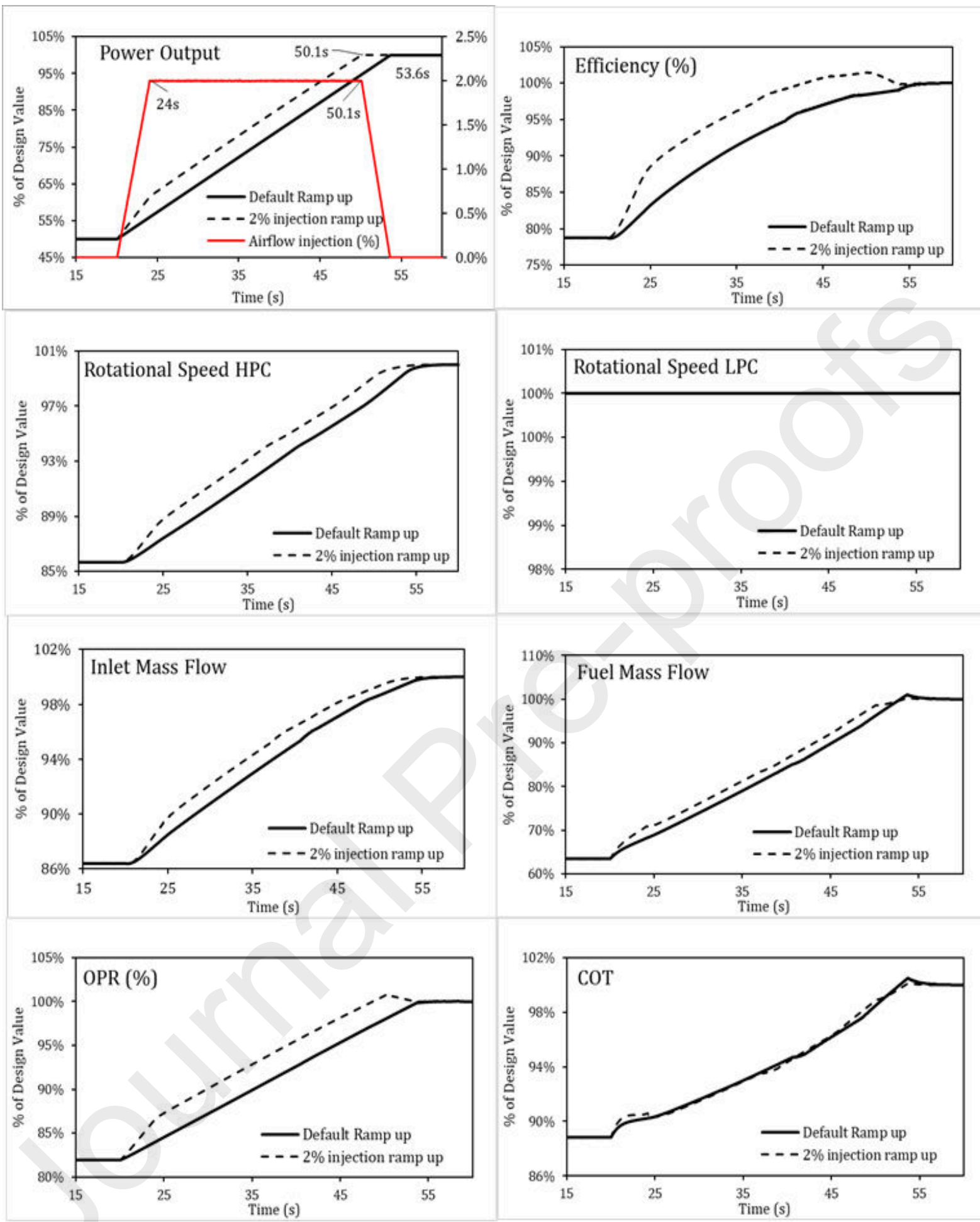

Figure 10: TS56 operational parameters for default and air injection ramp-up 

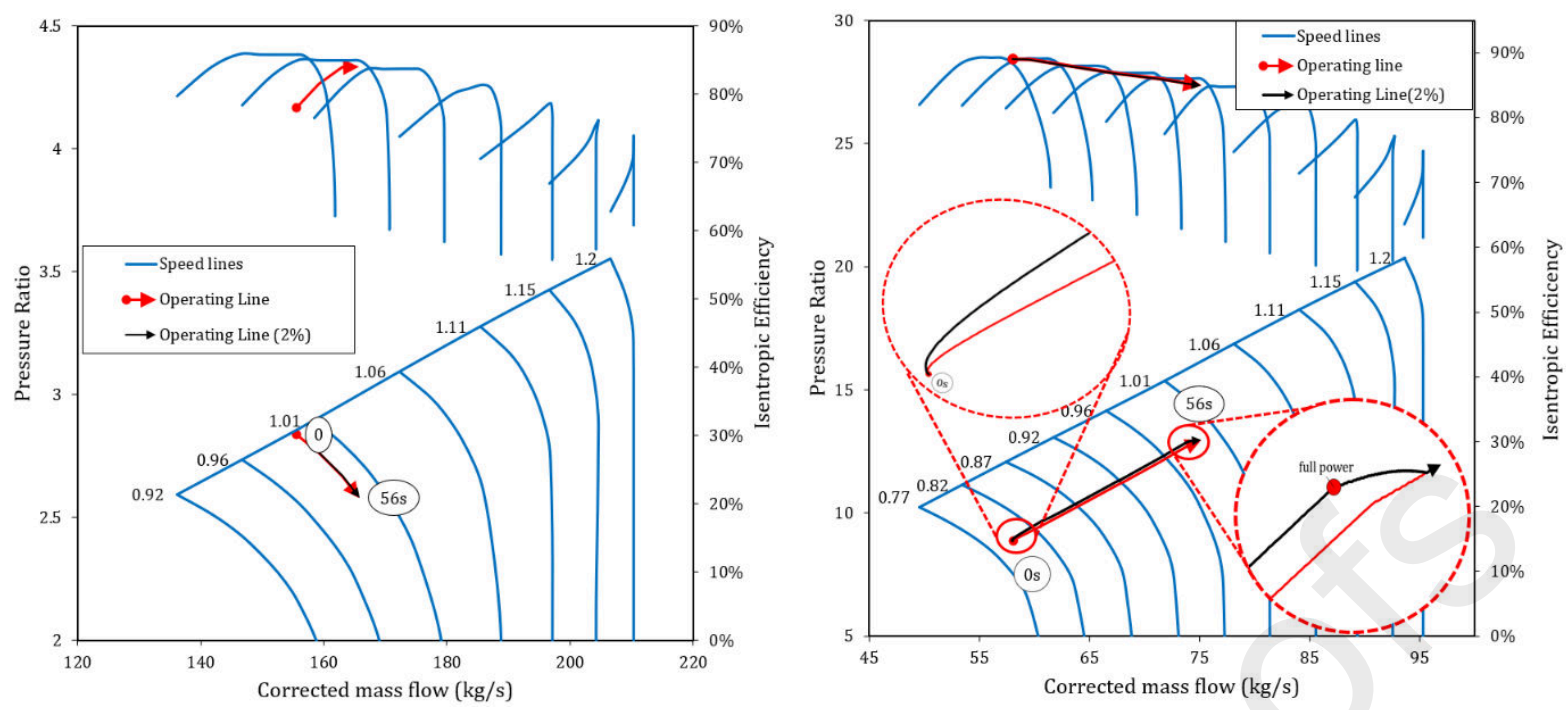

Figure 11: TS56 LPC (left) \& HPC (right) maps for default and air injection ramp-up

The ramp rate benefits achieved are computed using Equation 9. The improvements in ramp rates are plotted in Figure 13 which also indicates the required increase in fuel consumption for the ramp-up. The figure shows a steady increase in ramp rate and fuel consumption as the injected airflow increases. Increments of up to $85 \%$ in ramp rates are attainable with the maximum flow injection of $9.1 \%$, amounting to $1.6 \%$ increase in fuel consumption. The figure also points to the minimum HPC surge margin (SM) available during the ramp-ups at the base of the bar chart. A SM above $10 \%$ at the maximum injection percentage suggests adequate HPC operational safety during the ramp-up. The SM of the LPC is not considered as its pressure ratio reduces during the ramp-up.

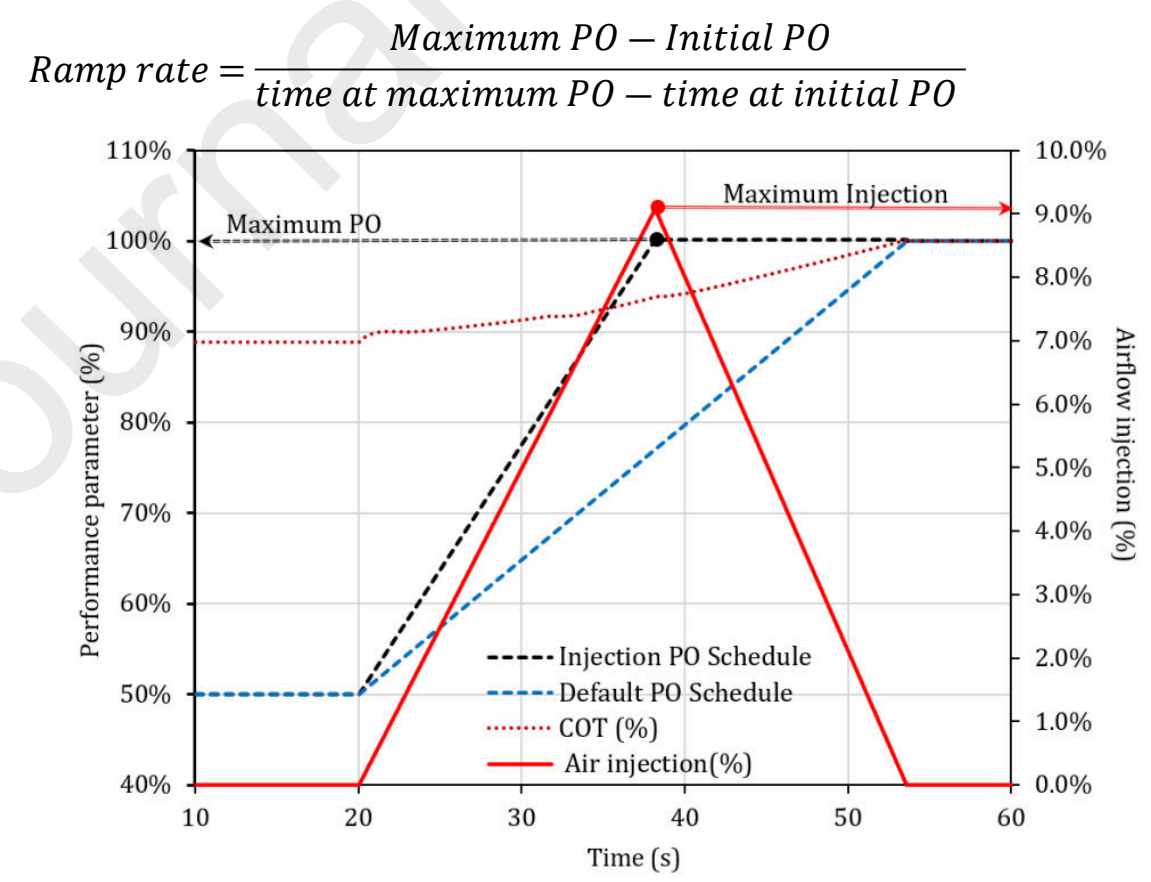

Equation 8 
Figure 12: Maximum air injection (9\%) schedule with corresponding ramp rate -TS56

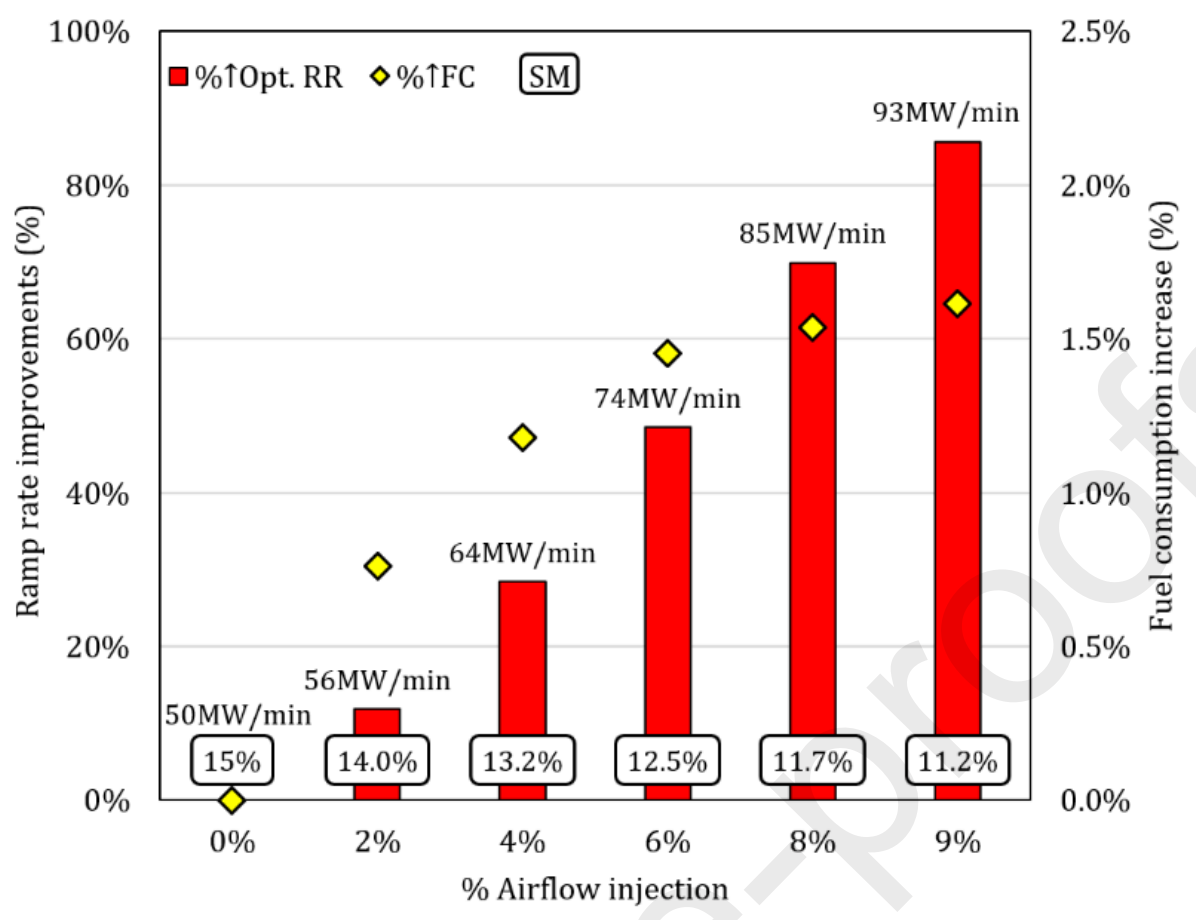

Figure 13: Ramp rate benefits of airflow injection on TS56

\section{TSI118 Ramp Rate and Compressor Behaviour}

Following the methodology described, augmented ramp rates are also evaluated for TSI118. The architectural differences between TS56 and TSI118 result in a slight variation in operation during injection ramp up. These distinctions are analysed by studying the operating parameters and the characteristic maps of the compressors. Figure 14 shows the maps of the LPC and HPC with operating lines for default and injection ramp-ups. As mentioned earlier, the design of TSI118 allows for speed variation on both compression sections (LP and HP) as shown in the figure. During the ramp-up, both compressor sections accelerate to higher speeds, increasing OPR and ingested airflow. The increased flow coupled with an increase in combustion temperature improves power output and thermal efficiency of the engine. The resistance to rotation (inertia) included in the computation results in a higher COT rise at the beginning of the ramp-up that brings about a faster increase in fuel flow. Wider nondimensional speed variations are observed for the LPC than the HPC; which is mainly a result of the increase in ingested airflow. For the injection ramp-up scenario, the increased airflow through the turbine augments its work and accelerates the compressors faster. This results in a higher-pressure ratio on both compressors when compared to the default ramp up. Despite the lower speed variation on the HPC, a higher pressure increase is noticed during the injection ramp up than on the LPC. This occurs to adjust the corrected mass flow into the turbine section. When the rated capacity of the engine is achieved, the injection flow is reduced, and the operating lines of both compressors tend to the design 
point. The operating parameters during the default case and the $2 \%$ injection ramp-up are provided in Figure A5.
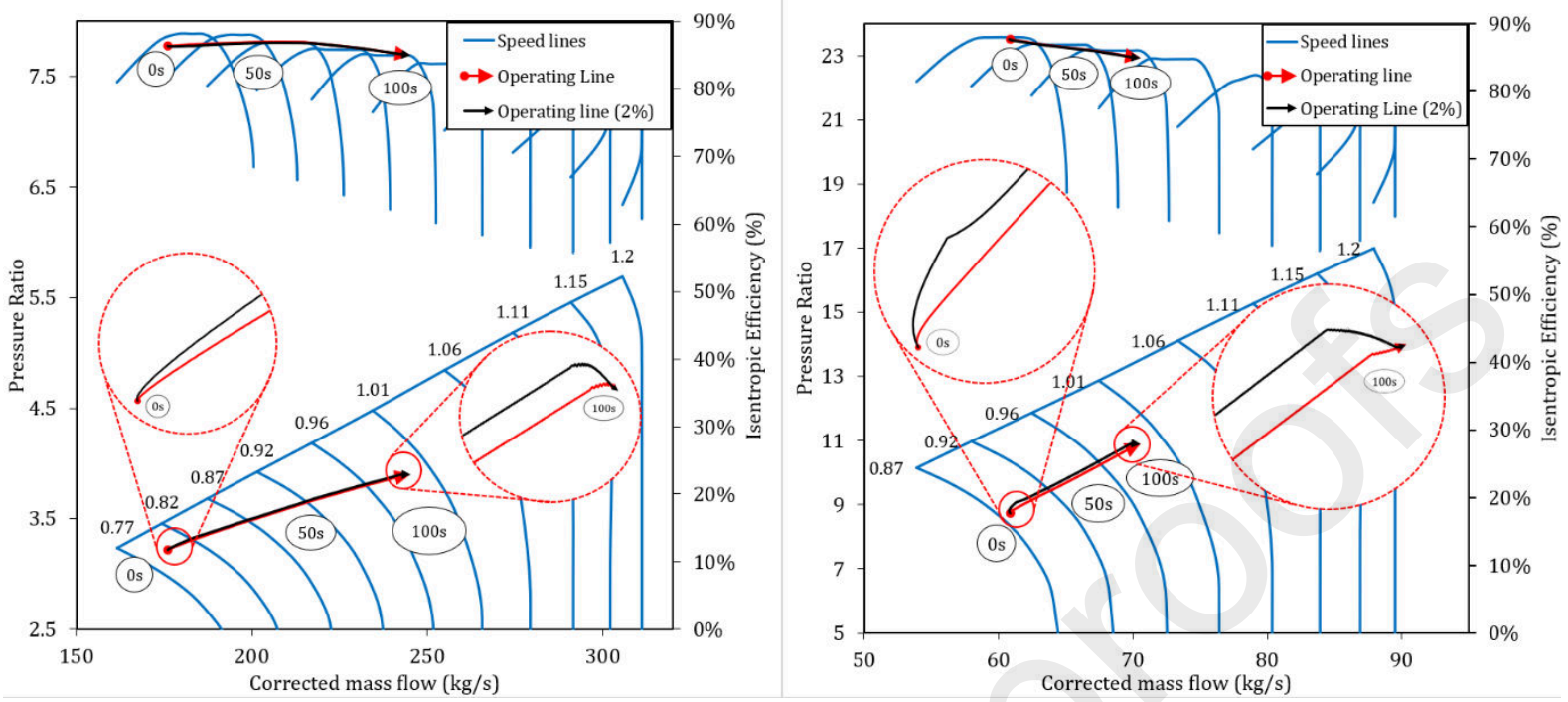

Figure 14: TSI118 LPC (left) \&HPC (right) operating line for default and air injection ramp-up

The ramp rate benefits from injecting compressed air into the compressor discharge of TSI118 are shown in

Figure 15. The figure also shows the increase in fuel consumption and minimum surge margins during the ramp-up. Notably, the ramp rate of TSI118 can be doubled by injecting $10 \%$ of the

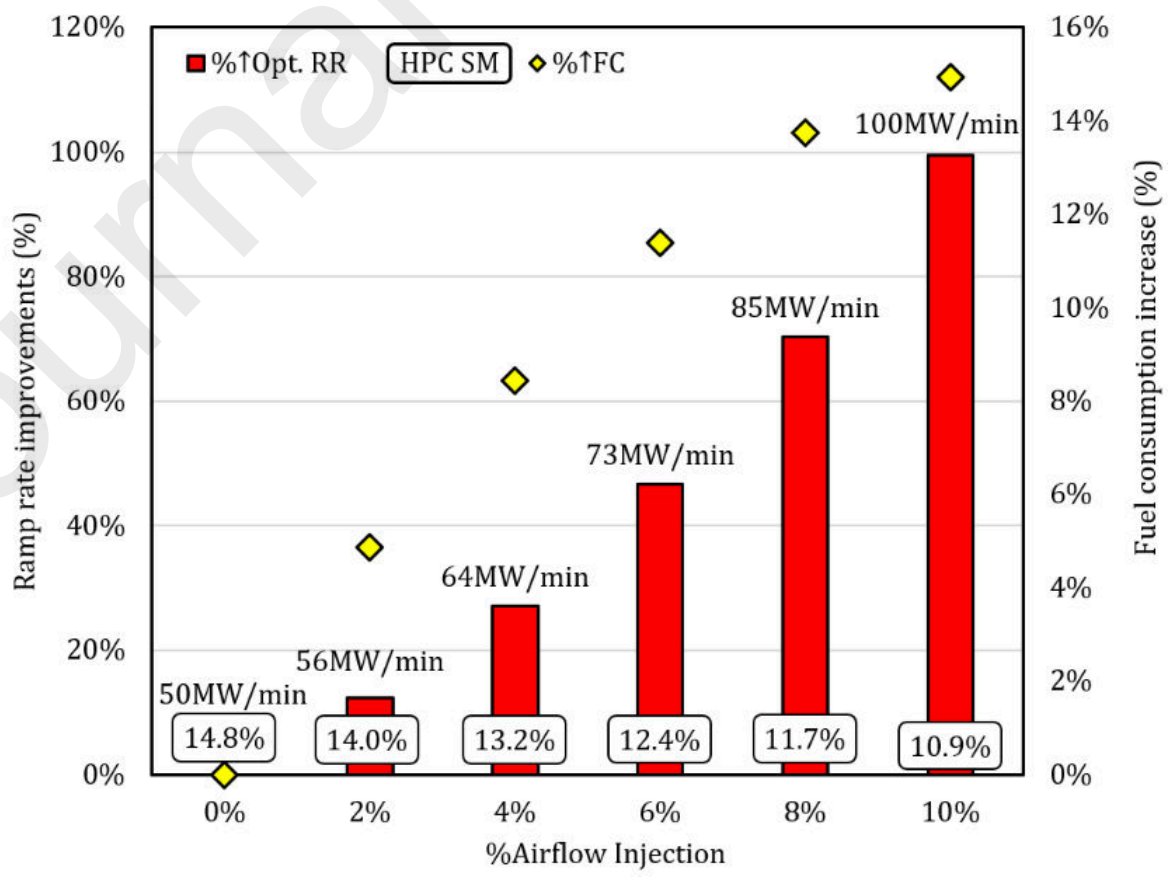

Figure 15: Ramp rate benefits of airflow injection on TSI118 
HPC discharge flow into the combustor. However, this causes a $15 \%$ increase in fuel consumption. This additional fuel penalty is due to the increased ingested airflow, intercooling implemented (reduced LPC CDT), coupled with a fixed COT schedule. The ramp rates with air injection show a steep positive gradient at $2 \%$ injection flow increments. The minimum HPC surge margin provided indicates an allowance of $11 \%$ for the $10 \%$ injection case. For the LPC, the minimum surge margin (6\%) occurs at the start of the operation and increases afterwards as shown on the left of Figure 14. These results show that at any given point in the operation, the surge point is not reached.

\section{OPERATIONAL CONCERNS DURING INJECTION RAMP UPS}

In addition to reduced SM, some operational parameters could limit the amount of airflow injection during ramp-up. Increments in TET and engine shaft speed are investigated here for limitations to airflow injections. Figure 16 presents the average trend deviations of combustor outlet temperature (COT) and TET for both engines at different injection rates. The deviations, approximated using the RMSE, suggest a negligible variation of COT during ramp-up with increased injection rates for both GTs. Nonetheless, both plots show positive trends for TET RMSE as injection rates increase. For similar COT deviations, TSI118 shows higher TET variations. The plots indicate that higher injection rates result in increased TET, which could compromise turbine blade life, despite the effort to maintain COT. It further shows that higher OPR engines are more prone to the TET rise during injection ramp up than lower ones. The intercooling implemented on TSI118 does not improve its thermal performance as higher pressure ratio increments are observed for the HPC than the LPC due to its proximity to the injection location.

Normalised speed deviations and increase in acceleration for both GTs are provided in Figure $\mathbf{1 7}$ for the injection scenarios considered. The LP shaft of TS56 is intentionally omitted as its architecture does not allow for speed variation. Positive trends are observed for both parameters with increasing injection percentages on both plots. Although, milder speed deviations are observed for the HP shaft of TS56 in comparison to the LP and HP shafts of TSI118. These translate to higher percentage increments in the acceleration of TSI118's shafts than TS56. The difference is explained by the faster increase in turbine work of TSI118 due to its lesser HPC work from intercooling. Consequently, the increased surplus power improves acceleration. Wider speed deviations and higher increments in acceleration can also be observed for TSI118's HP shaft in comparison to its LP. The effect is credited to the faster pressure ratio increase of the HPC; which increases further at superior injection percentages. However, it is noteworthy that the absolute acceleration of the HP shaft is lower than that of the LP for TSI118 as it rotates at a much faster speed. Conclusively, the figure informs of increased speed and acceleration during injection ramp-ups for both GTs. While the speed would not limit the air injection percentage (as it does not surpass the design value), the increase in acceleration could result in unacceptable vibration which will ultimately constrain the injection during ramp-up. 

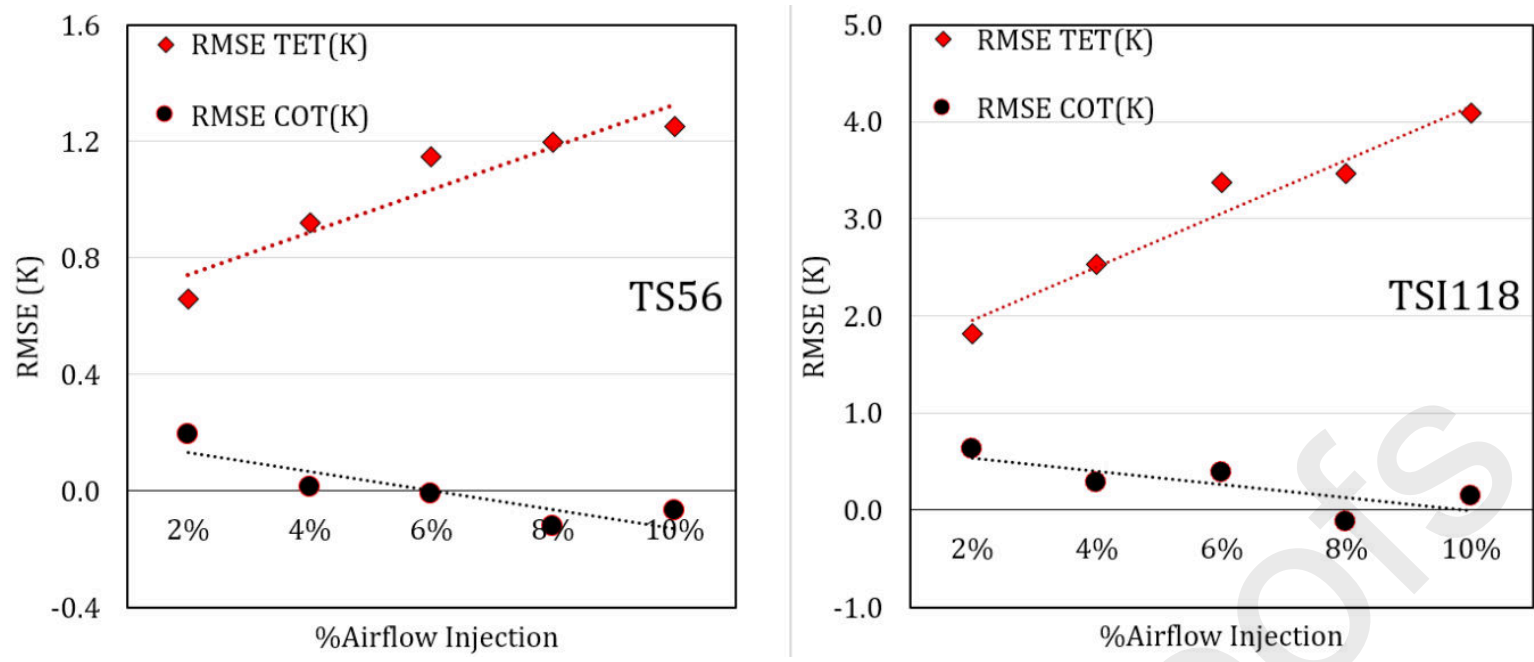

Figure 16: COT and TET RMSE by injection percentages for TS56 (left) and TSI118 (right)
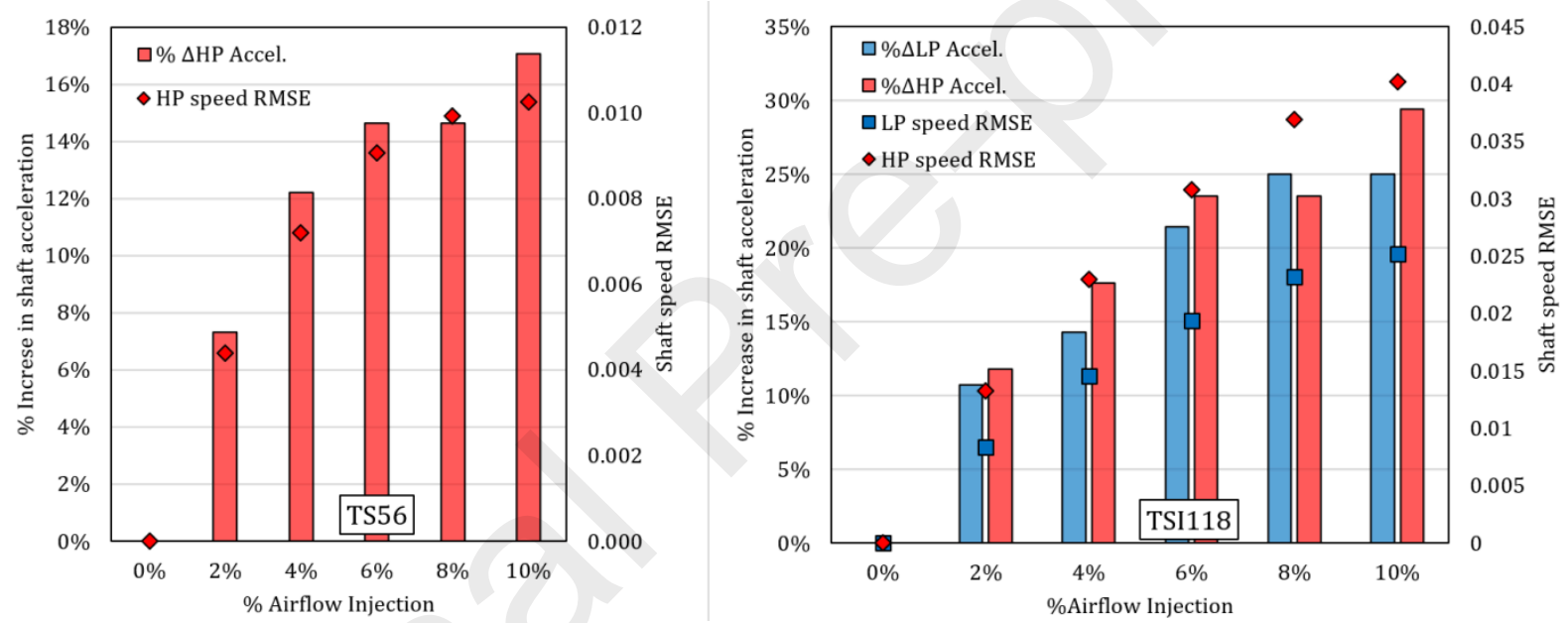

Figure 17: Shaft speed RMSE and increase in acceleration for TS56 (left) and TSI118 (right)

\section{CONCLUSIONS}

This study explored the benefits of compressed airflow injection into multi-spool aero-derivative gas turbines for power augmentation and ramp rate improvements for two engine configurations. Crucially, the work highlights the ramp-up capability that is essential to support renewable sources of power during a short-fall in power output.

The key findings show that the steady-state analysis for power augmentation shows:

- Airflow injection of $15 \%$ (wrt HPC discharge flow) resulted in power augmentation of $27 \%$ and 37\% for TS56 and TSI1 18 respectively, without surge. The LP spool of TSI118 showed a propensity to overspeed with a relative speed of 1.06 . Above $8 \%$ airflow injection, there is a sharp unfavourable rise in the HPC pressure ratios towards surge (for both engines) as shown 
in their compressor maps. With $8 \%$ injection limit for steady-state operation, the increase in power output is $16 \%$ and $21 \%$ respectively. These values are with respect to no air injections.

- Better power augmentation for TSI118 is attributed to the variable speed LP spool, the intercooler and higher OPR.; nevertheless, TS56 shows better thermal efficiency during air injection.

- Airflow injection modifies the compressors operating points as the HPC operation tends towards surge for both engines. Some differences in the LPC behaviour were observed, given that for the TS56 case, the rotational speed is fixed but variable for TSI118.

The transient analysis shows:

- Ramp rates of up to $85 \%$ and $100 \%$ are feasible for TS56 and TSI1 18 respectively. This is achieved with $9.1 \%$ and $10 \%$ limits of air injection in their respective operations, and without reaching their compressor surge points. Their ramp rate improvements values are from $50 \mathrm{MW} / \mathrm{min}$ to $93 \mathrm{MW} / \mathrm{min}$ and $100 \mathrm{MW} / \mathrm{min}$ respectively.

- The maximum air injection ramp-up raises the fuel consumption of TS56 by $1.6 \%$ and that of TSI1 18 by $15 \%$. This further highlights an advantage of the former over the latter, in terms of thermal efficiency.

- Airflow injection during ramp-up resulted in increased acceleration of the variable speed shafts of TS56 and TSI1 18 that increased at higher injections. In comparison, the HP and LP spools of TSI1 18 showed higher acceleration than the HP spool of TS56. Hence, the mechanical limits of these are worthy of study with respect to shaft vibrations.

It has been shown that the larger of the two engines (TSI118) allows for more airflow injection that brings about higher ramp-up rate. These improvements help to meet the increased response rate of gas turbines to back-up renewables.

\section{ACKNOWLEDGEMENT}

This study is part of TURBO-REFLEX project that has received funding from the European Union's Horizon 2020 research and innovation programme, under grant agreement No. 764545.

\section{Acronyms}

$\begin{array}{ll}\text { 1-15 } & \text { Location on Engine Schematic } \\ \text { ADGTs } & \text { Aeroderivative Gas Turbines } \\ \text { CCGT } & \text { Combined Cycle Gas Turbine } \\ \text { CDT } & \text { Compressor Discharge Temperature, K } \\ \text { CMF } & \text { Corrected Mass Flow, kg/s } \\ \text { cmf } & \text { Constant Mass Flow } \\ \text { COT } & \text { Combustor Outlet Temperature, K } \\ \text { DP } & \text { Design Point }\end{array}$


EGT Exhaust Gas Temperature, K

GE General Electric

GT Gas Turbine

HP High Pressure

ICV Intercomponent Volume Method

IMF Inlet Mass Flow

ISO International Organization for

Standardization

LP Low Pressure

OEM Original Equipment Manufacturer

OPR Overall Pressure Ratio

PO Power Output, MW

PT Power Turbine

RMSE Root Mean Square Error

SM Surge Margin

TET Turbine Entry Temperature, $\mathrm{K}$

TS56 Two Spool 56MW

TSI118 Two Spool Intercooled 118MW

VIGV Variable Inlet Guide Vanes

VSVs Variable Stator Vanes

WRT With Respect To

\section{Greek Symbols}

$\varepsilon \quad$ Effectiveness

$\checkmark \quad$ Heat capacity ratio

\section{Subscript}

$\begin{array}{ll}\text { amb } & \text { ambient } \\ \text { DP } & \text { air } \\ \text { g } & \text { design point } \\ \text { OD } & \text { off-design } \\ \text { comb } & \text { combustor }\end{array}$

\section{Nomenclature}

$\begin{array}{ll}\mathrm{a}_{1}-\mathrm{a}_{5} & \text { terms of respective equations } \\ \mathrm{b}_{1}-\mathrm{b}_{6} & \text { terms of respective equations } \\ \mathrm{c}_{1}-\mathrm{c}_{5} & \text { terms of respective equations } \\ \mathrm{d}_{1}-\mathrm{d}_{5} & \text { terms of respective equations } \\ \mathrm{Cp} & \text { Specific Heat Capacity, } \mathrm{KJ} / \mathrm{KgK} \\ \mathrm{I} & \text { Inertia, } \mathrm{kg} / \mathrm{m}^{2} \\ \mathrm{~N} & \text { shaft speed, rpm } \\ \mathrm{P} & \text { Pressure, bar } \\ \mathrm{Pr} & \text { pressure ratio } \\ \mathrm{SP} & \text { surplus power }(\mathrm{MW}) \\ \mathrm{T} & \text { Temperature, } \mathrm{K}\end{array}$


Air Mass Flow, Kg/s 


\section{APPENDIX A}

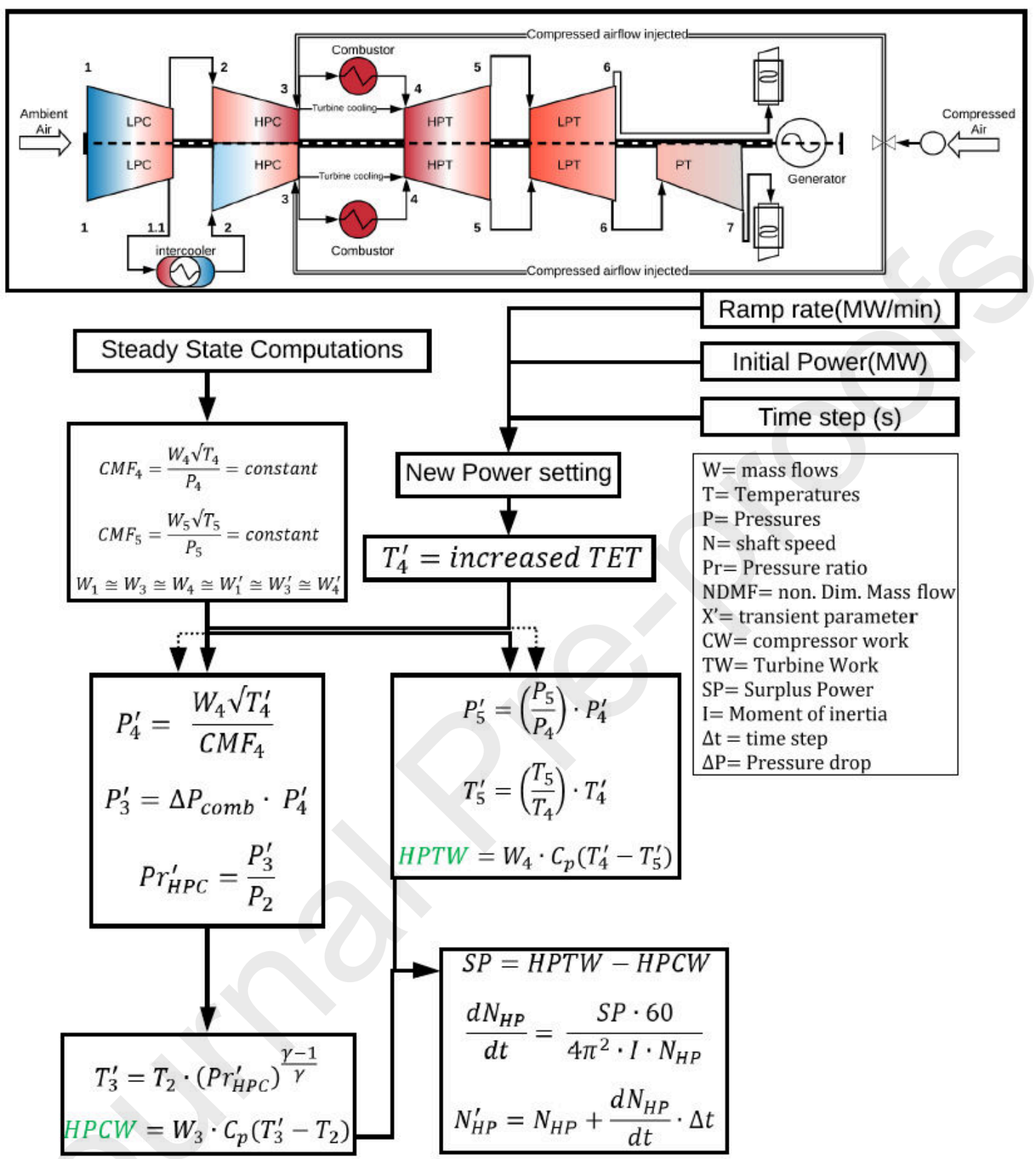

Figure A1: Flowchart for Constant Mass Flow (cmf) method of transient simulation 


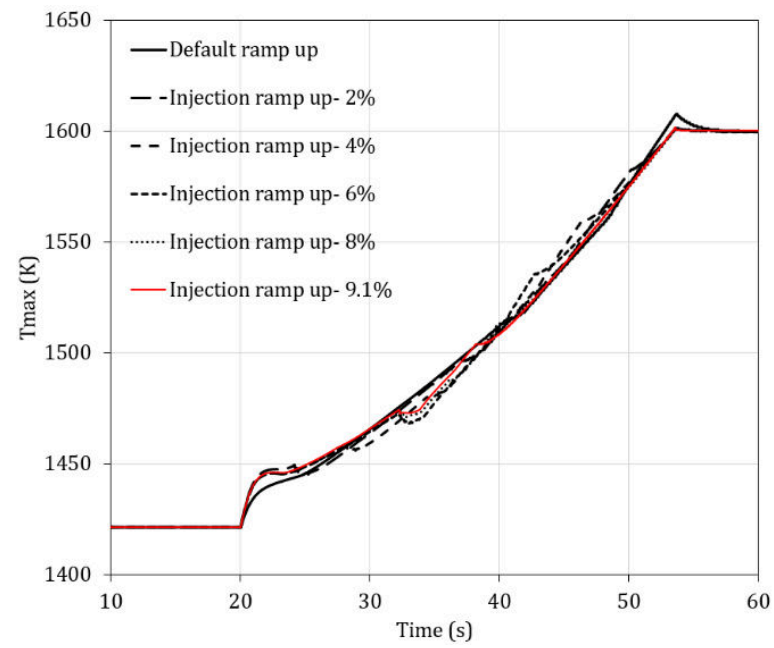

Figure A2: Identical operating lines for default and injection ramp ups-TS56

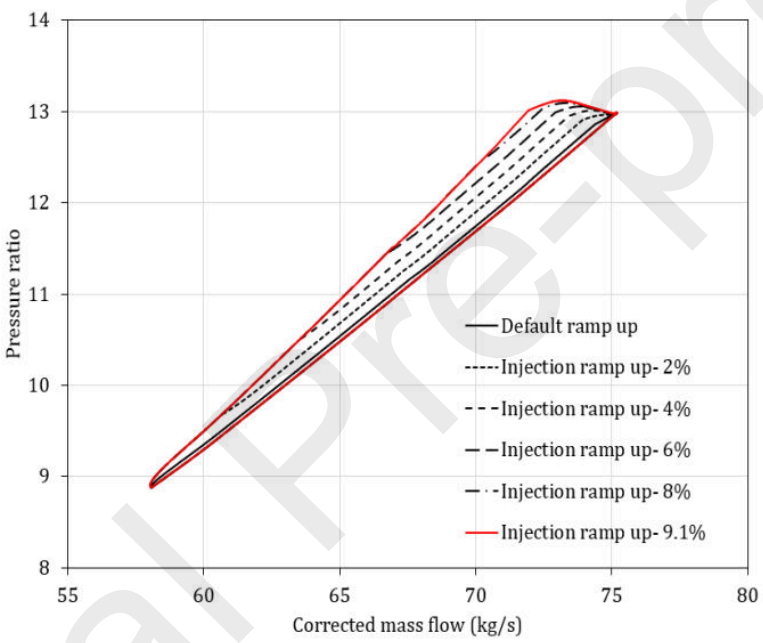

Figure A3: HPC operating lines for default and injection ramp ups-TS56

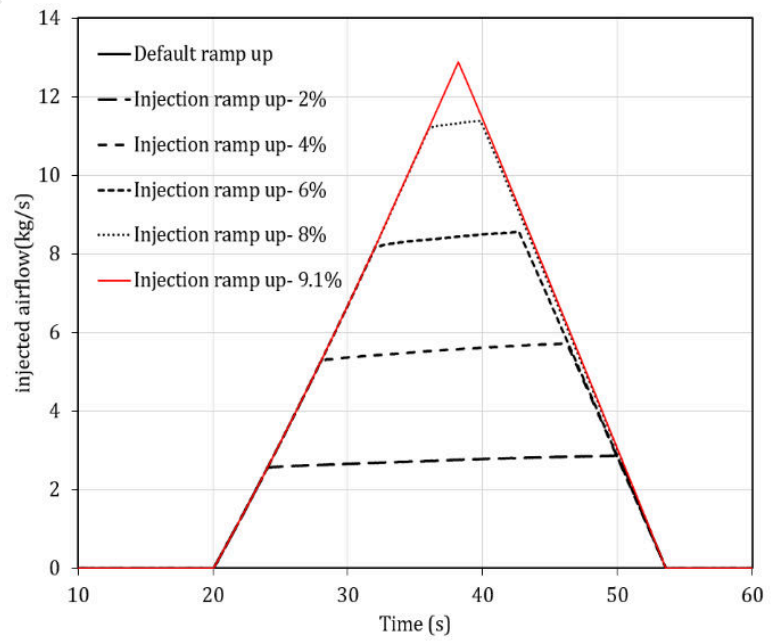

Figure A4: Airflow injection schedules for ramp ups-TS56 


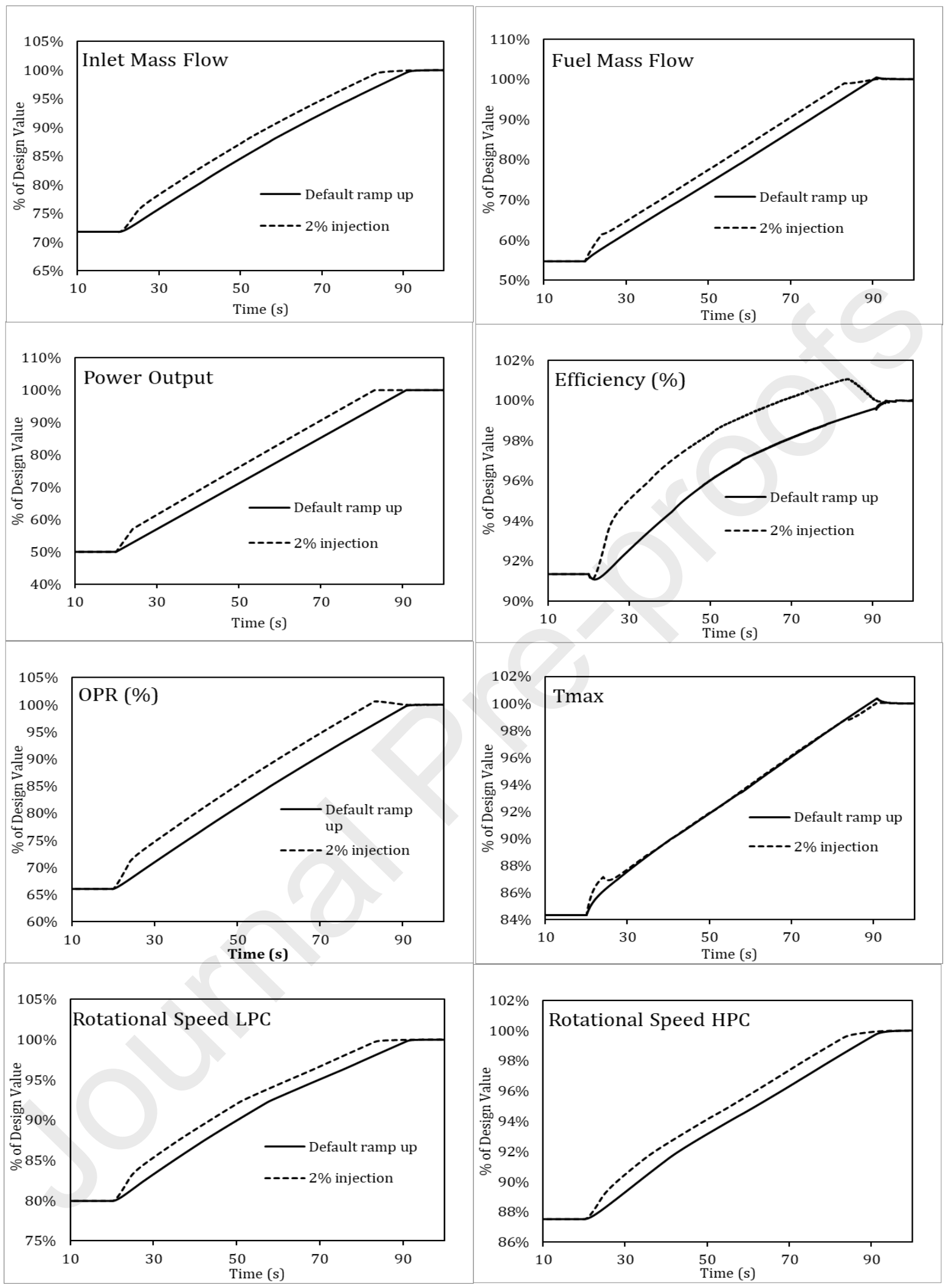

Figure A5: Operational parameters during default and injection ramp up- TSI118 


\section{References}

[1] U.S. Energy Information Administration, "International Energy Outlook 2019," U.S. Energy Information Administration, 2019.

[2] J. DiCampli and D. Laing, "State of the Art Hybrid Solutions for Energy Storage for Grid Firming," GE Power, June 2017. [Online]. Available: https://www.ge.com/content/dam/gepowerpgdp/global/en_US/documents/product/hybrid/GE\%20PGE\%202017\%20Hybrid\%20paper.pdf. [Accessed August 2019].

[3] T. W. Overton, "CPV Sentinel Energy Project, Desert Hot Springs, California," Power, vol. 158, no. 9, 1 September 2014.

[4] Gridwatch, "G.B. National Grid Status," June 2020. [Online]. Available: https://www.gridwatch.templar.co.uk/. [Accessed 15 June 2020].

[5] H. Chen, T. N. Cong, W. Yang, C. Tan, Y. Li and Y. Ding, "Progress in electrical energy storage system: A critical review," Progress in Natural Science, vol. 19, no. 3, pp. 291-312, 2009.

[6] B. Kraft, P. Perri and A. Quintero, "PowerPhase: Whitepapers," [Online]. Available: https://powerphase.com/wp-content/uploads/2017/11/Turbophase-Dry-Air-Injection-on-AerosFinal.pdf. [Accessed 15 June 2020].

[7] Federal Aviation Authority (FAA), Airplane Turbofan Engine Operation and Malfunctions: Basic Familiarization, FAA, 2016.

[8] K. Abudu, U. Igie, O. Monervino and R. Hamilton, "Gas Turbine Efficiency and Ramp Rate Improvement through Compressed Air Injection," Journal of Power Engineering- Under Review, 2020.

[9] U. Igie, M. Abbondanza, A. Szymański and T. Nikolaidis, "Impact of Compressed Air Energy Storage Demands on Gas Turbine Performance," ASME Journal of Engineering for Gas Turbines and Power- Under Review, 2019.

[10] M. Nakhamkin, B. Patashnik and R. H. Wolk, "Humidified Air Injection Raises Peak Turbine Output," Power Engineering, 11 January 1999.

[11] J. D. Wojcik and J. Wang, "Feasibility study of Combined Cycle Gas Turbine (CCGT) power plant integration with Adiabatic Compressed Air Energy Storage (ACAES)," Applied Energy, vol. 221, pp. 477- 489, 2018.

[12] M. J. Kim and T. S. Kim, "Integration of compressed air energy storage and gas turbine to improve the ramp rates," Applied Energy, vol. 247, pp. 363-373, August 2019.

[13] C. Salvini, "Performance Analysis of Small Size Compressed Air Energy Storage Systems for Power Augmentation: Air Injection and Air Injection/Expander Schemes," Journal of Heat Transfer Engineering, vol. 39, no. 3, pp. 304-315, 2018.

[14] N. M. Jubeh and Y. S. Najjar, "Power augmentation with CAES (compressed air energy storage) by air injection or supercharging makes environment greener," Energy, vol. 38, no. 1, pp. 288235, February 2012. 
[15] J. H. Jeong, J. H. Yi and T. S. Kim, "Analysis of options in combining compressed air energy storage with a natural gas combined cycle," Journal of Mechanical Science and Technology, vol. 32, no. 7, pp. 3453-3646, July 2018.

[16] M. A. Gonzalez-Salazar, T. Kirstena and L. Prchlikb, "Review of the operational flexibility and emissions of gas- and coal-fired power plants in a future with growing renewables," Renewable and Sustainable Energy Reviews, vol. 82, no. 1, pp. 1497-1513, February 2018.

[17] L. Balling, "Fast cycling and rapid start-up: New generation of plants achieves impressive results," Modern Power Systems, vol. 31, no. 1, pp. 35-40, January 2011.

[18] GE Power, "Power FlexEfficiency," April 2014. [Online]. Available: https://www.ge.com/content/dam/gepowerpgdp/global/en_US/documents/service/gas\%20turbine\%20services/power-flexefficiencybrochure.pdf. [Accessed August 2019].

[19] GE Power, "LM6000 Power Plants (50/60 Hz)," General Electric Company, 2016.

[20] GE power, "LMS100 Power Plants," General Electric Company, 2017.

[21] T. Nikolaidis, "The Turbomatch Scheme," 2015.

[22] U. Igie and O. Minervino, "Impact of Inlet Filter Pressure Loss on Single and Two-Spool Gas Turbine Engines for Different Control Modes," J. Eng. Gas Turbines Power, vol. 136, no. 9, September 2014.

[23] International Organization for Standardization (ISO), "Gas Turbine - Acceptance Test (ISO 2314)," ISO, 2009.

[24] P. P. Walsh and P. Fletcher., Gas Turbine Performance, 2nd ed., Oxford: Blackwell Publishing Company, 2004, p. 65.

[25] C. CangTo, "Slideshare - Axial Compressor Theory," 28 January 2010. [Online]. Available: https://www.slideshare.net/CangToCheah/axial-compressor-theory-stagebystage-approach-28thjanuary-2010. [Accessed 16 May 2019].

[26] J. K. Min, J. H. Jeong and K. S. Kim, "High Temperature Heat Exchanger Studies for Applications to Gas Turbines," Heat and Mass Transfer, vol. 46, no. 2009, pp. 175-186, 2009.

[27] B. N. P. Sanjay, "Energy and exergy analysis of intercooled combustion-turbine based combined cycle power plant," Energy, vol. 59, no. 2013, pp. 277-284, 2013.

[28] H. Saravanamuttoo, G. Rogers and H. Cohen, Gas Turbine Theory, New Delhi: Pearson education Ltd., 2001, p. 276.

[29] A. H. Lefebvre and D. R. Ballal, Gas Turbine Combustion: Alternative Fuels and Emissions, Boca Raton, Florida: Taylor \& Francis Group, LLC, 2010, pp. 153-154.

[30] R. K. Bhargava, M. Bianchi, D. P. A, G. N. d. Montenegro and A. Paretto, "Gas Turbine Based Power Cycles- A State-of-Art Review," in International Conference on Power Engineering, Hangzhou, 2007.

[31] M. J. Reale, "New High Efficiency Simple Cycle Gas Turbine- GE's LMS100," General Electric Company, 2004. 
[32] R. Wilcock, J. Young and J.H.Horlock, "The Effect of turbine Blade Cooling on the Cycle Efficiency of Gas Turbine Power Cycles," Journal for Engineering for Gas Turbines and Power, vol. 127, no. January, pp. 109-120, January 2005.

[33] C. Salvini, "CAES Systems Integrated into a Gas-Steam Combined Plant: Design Point Performance Assessment," energies, vol. 11, no. 2, p. 17, 2018.

[34] V. Singh, L.-U. Axelsson and W. Visser, "Transient Performance Analysis of an Industrial Gas Turbine Operating on Low Calorific Fuels," Journal of Engineering for Gas Turbine and Power, vol. 139, no. 5, p. 7, May 2017.

[35] Calpine, "Generator Interconnection Data Sheet," Pacific Gas and Electric Company, Gilroy, 2000. 


\section{Highlights}

- Needed flexibility enhancements for aeroderivative engines enabled by air injection

- Airflow injection of $8 \%$ augments power output of aeroderivatives up to $21 \%$

- Potential for high-pressure compressor surge at higher air injection rate above $15 \%$

- Ramp-up rate of aeroderivative engines can be doubled with airflow injection of $10 \%$

- Increased temperature gradient and acceleration can limit ramp rate benefits 


\section{Declaration of interests}

The authors declare that they have no known competing financial interests or personal relationships that could have appeared to influence the work reported in this paper.

$\square$ The authors declare the following financial interests/personal relationships which may be considered as potential competing interests: 
2020-08-08

\title{
Aeroderivative gas turbine back-up capability with compressed air injection
}

\author{
Abudu, Kamal
}

Elsevier

Abudu K, Igie U, Roumeliotis I, et al., (2020) Aeroderivative gas turbine back-up capability with compressed air injection. Applied Thermal Engineering, Volume 180, November 2020, Article number 115844

https://doi.org/10.1016/j.applthermaleng.2020.115844

Downloaded from Cranfield Library Services E-Repository 